\title{
OCTUBRE DE 1934 EN MADRID: ACCIÓN COLECTIVA Y VIOLENCIA POLÍTICA ${ }^{1}$
}

\author{
por
}

\section{SANDRA SOUTO KUSTRÍN}

Departamento de Historia Contemporánea (CSIC).

RESUMEN: Este artículo pretende analizar los conflictos politicos violentos producidos en Madrid durante 1934, que culminaron en la insurrección de octubre de 1934, dedicando especial atención a la conformación, organización y funcionamiento de las Milicias Socialistas Madrileñas. Se intenta explicar esta conflictividad a través de los principates elementos que determinan la acción colectiva: los intereses, la organización, las oportunidades políticas, la movilización de recursos (tanto materiales como culturales) y la conformación de las identidades colectivas y solidaridades.

Palabras clave: España. Segunda República. Conflicto social. Violencia política.

ABSTRACT: The aim of this article is to analyse the violent political conflicts that happened in Madrid during 1934, and that culminated in the insurrection of October 1934. It specially attends to the formation, organization and functioning of the Madrid Socialist Militias. It mill explain these conflicts through the elements that determine collective action: interests, organiqations, political opportunities, cultural and material resource mobilization and the formation of collective identities and solidarities.

KEY worus: Spain. Second Republic, Social conflict. Political violence.

El estudio de los conflictos sociales y la violencia política adquiere cada vez un mayor interés para historiadores, politólogos y sociólogos. Pero son escasos los estudios sobre estos fenómenos en la historia de la España contemporánea que tengan en cuenta los trabajos y teorizaciones sobre ellos elaborados desde las más importantes corrientes de la sociología y politología anglosajonas, que estudian estos fenómenos como acciones colectivas racionales, definidas como «la acción conjunta de contendientes en busca de fines comunes». Por otra par-

1 Este trabajo ha sido posible gracias a una beca de la Comunidad Autónoma de Madrid. 
te, el estudio de estos aspectos en la provincia de Madrid durante la Segunda República se ha realizado de forma parcial: los análisis se centran en el desarrollo de las organizaciones sindicales y patronales y los conflictos laborales en la capital, y no tratan siquiera los grandes pueblos circundantes que concentran ya, en gran parte, a la población obrera de la región ${ }^{2}$. Hay por tanto una realidad poco conocida, la provincia de Madrid, y grandes lagunas: hace falta un análisis de todas las organizaciones obreras presentes; del papel jugado por los jurados mixtos; de los conflictos sociales violentos, de los resultados de las elecciones generales y municipales en toda la provincia, ...

En el primer tercio del siglo XX se asentó en España el repertotio de acción colectiva que Tilly denomina modular, autónomo y cosmopolita. En este contexto, la Segunda República vivió un proceso de movilización política sin precedentes, en el que tuvo un papel muy importante la juventud, como muestra la presencia de organizaciones específicamente juveniles vinculadas a los distintos partidos y el desarrollo de organizaciones estudiantiles. Cobraron importancia las mentalidades y las justificaciones de la violencia en todo el espectro político, excepto en la burguesía republicana. La violencia se veía como «medio explícito, sistemático, organizado ... de obtener objetivos políticos y sociales» y se desarrollaron nuevos tipos de acciones, que implicaron el surgimiento de nuevas formas de organización ${ }^{3}$. Las más novedosas fueton las milicias políticas, formaciones paramilitares creadas para el asalto al poder mediante la lucha armada. El fenómeno de las milicias fue extendido y común, pero no universal (fue rechazado, por distintas razones, por las JAP y por los anarquistas), y en ellas también destacó el papel de la juventud.

Pretendemos aquí analizar la conflictividad política violenta en Madrid en 1934, partiendo de las teorías de la acción colectiva, que consideran que en la conformación de ésta influyen los intereses y la percepción de éstos y de la realidad social en general, que dan lugar a definiciones compartidas de ésta; la organización, que incluye las redes de relaciones previas o paralelas, que no

2 La cita es de Tiı,1y, C., From Mobilization to Revolution, Nueva York, Mac Graw Hill, 1978, p. 55. Sobre Madrid, destacan los trabajos, en muchos aspectos pioneros, de Santos Julíá.

3 Sobre los repertorios de acción colectiva caracterizados, entre otras cosas, por el uso de medios de acción relativamente autónomos, la tendencia a participar como miembros o representantes de intereses especiales y asociaciones determinadas, a desafiar especialmente a autoridades nacionales y sus representantes directamente y la exposición de programas, lemas y signos comunes a los miembros, ver la última elaboración de C. Tilly en Tilı.Y, C., Popular contention in Great Britain (1758-1834), Cambridge (Massachusetts)-London (England), Hardvard University Press, 1995, especialmente capitulos 1 y 8 , en el que ha cambiado los nombres definitorios de los repertorios, introduciendo alguna nueva característica como la de modularidad (ya planteada por Tarrow, S., Power in movement, New York, Cambridge University Press, 1994), pero mantiene las caracteristicas generales de cada tipo de repertorio planteadas en TIL.Y, C., The Contentious French. Four Centuries of Popular Struggle, Cambridge, Belknap Press of Harvard University Press, 1986. La cita es de Aróślicul, J., «Introducción», en Ibid. (Coord), «La militarización de la politica durante la II Repúblicas, Historia Contemporánea, Bilbao, ñ. 11 (1994), pp. 24-25.

Hi.panis. LIX/3, núm. 203 (1999) 1063-1103 
tienen porqué coincidir con las otganizaciones formales también incluidas en este aspecto; la estructura de oportunidades políticas; la movilización de recursos (tanto materiales como culturales); y la conformación de las identidades colectivas y solidaridades, a través de la percepción de la realidad social dentro y fuera de las organizaciones y de todo el proceso de movilización de recursos y actuación colectiva mismos. Vamos a examinar, en primer lugar, los factores que condicionan la acción colectiva, y la conflictividad anterior a la revolución de octubre de 1934, lo que nos permitirá analizar y explicar las características que tuvo esta última en Madrid y sus consecuencias. Haremos hincapié en las posiciones reflejadas por las organizaciones obreras en prensa, mitines y conferencias, ya que eran los medios principales a través de los cuales podían recibir información los militantes de éstas, influyendo en su percepción de la realidad y en su conocimiento de las formas de acción colectiva: la utilización de éstas depende de los recursos, pero también de ela información posible al grupon; las relaciones socioeconómicas y políticas pueden indicar qué intereses serán planteados por los grupos sociales, pero, «a corto plazo, la propia articulación de sus intereses por estos grupos explica su conductan 4 .

\section{LOS CONDICIONANTES DE LA ACCIÓN COLECTIVA}

La elección de un determinado tipo de acción colectiva está influida por la consideración de «los propios éxitos y fracasos de los contendientes y las observaciones de éstos sobre otros grupos similares». En este sentido, destaca, en primer lugar, el modelo de acción de las huelgas revolucionarias de 1917 y 1930 en España, que los socialistas llamaban «revoluciones», aunque lo que habían realizado en ambos casos era una huelga general que contaba o esperaba contar con el apoyo de una conspiración militar propiciada por los republicanos. Existía otro modelo, que era el de la revolución rusa de 1917: el análisis del proceso tevolucionario en España era realizado por todas las organizaciones obreras, incluidas las socialistas, en función del ejemplo ruso. Había también un modelo negativo: la represión de los regímenes autoritarios o fascistas. Más importante que la formación de Falange era la percepción, por parte de las organizaciones obreras, de la CEDA como fascista, y la creencia en un peligro inminente de caida de España en un régimen fascista, que aumentó con los sucesos de febre-

4 Sobre las teorías de la acción colectiva, ver, además de las obras ya ciradas, entre otros muchos titulos y por no alargar este articulo, KJ_inderans, B., KuiEsi, H. y TArurow, S. (Eds.), From Structure to Action: Comparing Social Movements Research Across Culture, Greenwich (Connecticut), Jai Press, 1988; MeluCCr, A., Nomads of the Present. Social Movement and Individual Needs in Contemporary Society, Londres, Hutchinson Radius, 1989; Cruz, R., «La cultura regresa al primer planom, en CRUZ, R. y PĹREZ LIIDESMA, M. (Eds.), Cultura y movilización en la España Contemporánea, Madrid, Alianza, 1997 o el más reciente de LARAÑA, E., La construcción de los movimientos sociales, Madrid, Alianza, 1999. La primera cita es de Thrrow', S., Democraty and Disorder. Protest and Politics in Italy, 1965-1975, Oxford, Clarendon Press, 1989, p. 20; la segunda, de OBissscisal., A., Social Conflicts and Social Movements, Englewood Cliffs, Prentice Hall Inc., 1973, p. 33.

Iliphania, 1.IX/3, núm. 203 (1099) 1063-1103 
ro de 1934 en Austria, que «demostraron» la necesidad de realizar una «tevolución defensiva». El desarrollo de la República pasaba por el fascismo o la revolución social, polarización en la que se basaba el análisis de la situación española y que transmitieron a los trabajadores todas las organizaciones obreras ${ }^{5}$.

Para que se produzca una acción colectiva tiene que haber, también, un conflicto de intereses, definidos como las aspiraciones de un grupo y las ventajas y desventajas que puede obtener éste como consecuencia de las distintas posibilidades de interacción con ottos grupos, priorizando la vida económica, social y política y la percepción de éstas por los actores sociales ${ }^{6}$. En los cambios en la configuración de los intereses de los grupos sociales influyeron, en nuestro caso, las transformaciones económicas, la ruptura de la conjunción republicana-socialista y el triunfo de la CEDA en las elecciones de 1933.

En Madrid, la crisis económica de los años 30, de la que la patronal culpó a las reformas sociales republicanas, se manifestó en un estancamiento de la mayoría de los sectores industriales, mientras que otros, como la construcción y sectores dependientes de ésta, sufrían grandes pérdidas. Aumentó el desempleo, lo que redujo el consumo, llegando así la crisis a los comercios. En el aspecto asociativo, Madrid era una de las primeras provincias del Estado en número de obreros sindicados, que se repartían entre la UGT (la mayor: organización obrera de Madrid) y la CNT. En los años 30, con los cambios en las condiciones sociales, la «riada» de afiliaciones y la aparición de grandes masas de obreros de escasa cualificación en grandes sociedades anónimas, la estructura organizativa y la práctica sindical de la UGT no resultaban válidas. Esto favoreció el crecimiento de la CNT, en especial de sus organizaciones de camareros y construcción. El sindicalismo del PCE tenía escasa implantación, al igual que el católico. En telación con los partidos políticos obreros, la afiliación al PSOE fue creciendo progresivamente durante la Segunda República, llegando a 5.420 militantes al terminar 1933. En abril de 1934, existían agrupaciones socialistas, además de en la capital, al menos en Vallecas, Guadarrama, San Lorenzo de El Escorial, Vicálvaro, Carabanchel Alto, Robledo de Chavela, El Escorial, Pozuelo, Colmenar Viejo, Barajas, Leganés, Aranjuez, Alcalá de Henares, Navacerrada, Villaverde, Puente de Vallecas, Chamartín de la Rosa, Villaverde (bartio de Usera), Carabanchel Bajo y Ciempozuelos. Por su parte, el PCE tenía en Madrid capital 883 afiliados en 1933, y su organización juvenil,

5 La cita está tomada de Tuı,y, C., From Mobilization..., op. cit., p. 157; ver también Popular contention..., op. cit., p. 40. La visión de una sociedad polatizada entre fascismo y socialismo no era exclusiva de las organizaciones obreras: la asamblea patronal del comercio de Madrid, en julio de 1933, a la que se adhirió la Federación Patronal Madrileña (FPM, la más importante organización del sector industrial madrileño), habló de la «inminente caída de España en la dictadura socialista o fascista» (JUI.ıA, S., Madrid 1931-1934: De la fiesta popular a la luctha de clases, Madrid, Siglo XXI, 1984, p. 291). 54.

6 La definición de intereses se puede ver en Tus., C., From Mobilization..., op. cit., pp. 7 y

Hipania, LIX/3, núm. 203 (1999) 1063-1103 
la UJCE, 500. Tenía organizaciones también en Carabanchel, Tetúan y Vallecas. $\mathrm{El}$ informe presentado en su Conferencia Regional hablaba de un «aumento de la organización ... del Partido en algunos pueblos como Pinto, Arganda, Hortaleza, Villaverde», pero planteaba también su inactividad: «falta de vida política en las células. Reacción insuficiente o tardía frente a los acontecimientos actuales». Había también organizaciones de otros pequeños partidos, como la Izquierda Comunista ?.

La colaboración socialista con los gobiernos del primer bienio fue objeto continuo de debate interno en las organizaciones socialistas. También algunos partidos republicanos respondieron al crecimiento de la reacción patronal pidiendo la salida de los socialistas del gobierno. En septiembre de 1933, AlcaláZamora nombró un nuevo gabinete, presidido por Lerroux, en el que quedaron fuera los ministros del PSOE. Ésto fue considerado por este partido una traición, lo que, junto a la pérdida de la legislación social, destacó en todas sus tribunas. R. Henche explicó la reacción de los socialistas madrileños en la reunión del Comité Nacional del PSOE del 18 y 19 de septiembre de 1933: «la gente habla ... del asalto al Poder..., no se le puede hablar de coaliciones con los republicanos». Se mantenía todavía abierto el camino legal hacia el socialismo, aunque en la Federación de Juventudes Socialistas (FJS) la orientación hacia una opción revolucionaria violenta era clara ya antes de las elecciones de noviembre de 1933: «ni democracia burguesa ni dictadura burguesa, sino dictadura del proletariado». La derrota en las elecciones fue vista como la entrega de la República a la reacción, y exaltó más sus posiciones: Renovación, órgano de la FJS, planteó que esestas cortes ... no representan la voluntad popular... Vivitán lo que el pueblo y el proletariado tarden en prepararse para clausurarlas». La situación se relacionó claramente con los ejemplos internacionales: «no podemos ... perder el tiempo encareciendo una preparación que nunca se verá completada ... Por esperar a ello se hundió la Socialdemocracia alemana, como se hundirá en breve la austríacas. Se justificaban, así, planteamientos revolucionarios violentos como «única solución»: «no queda más remedio que vencer matando o perder muriendo", "no ya sólo para alcanzar nuestro programa maximalista, sino para defender el programa minimalistay. Pero, en Madrid, la candidatura más votada fue la socialista, que también triunfó en algunas de las localidades próximas, como Carabanchel Bajo, Vallecas y Chamartín. Renovación consideró a la juventud el eje central de este triunfo («Madrid ha sido testigo de la influencia socialista de nuestra joven generación»), que les dio una gran con-

7 Para la UGT y la CNT en Madrid capital en los primeros años 30 ver yulıA, S., Madrid, 1931-1934..., op. cit., passim. Sobre el PSOE, el número de afiliados está tomado de TUÑ́N DE: LARA, M., El moumiento obrero en la historia de España II (1910-1936), Madrid, Sarpe, 1985, p. 308; las agrupaciones socialistas en los pueblos, en Fundación Pablo Iglesias (FPI), AH 22-4, «Relaciones de envios certificados", pp. 21 y 22; ver en CRUz, R., «La organización del PCE (19201934)", Estudios de Historia Social, Madrid, n ${ }^{\circ} .31$, (octubre-diciembre de 1984), p. 265 los datos sobre el PCE, y p. 297, los de la UJCE; la cita, en Archivo Histórico del PCE (AH PCE), film VIII (114).

Hi.jpanit, 1.[X/3, núr. 203 (1999) 1063-1103 
fianza en su capacidad para la acción insurreccional: «Madrid ... se ha pronunciado por la dictadura del proletariado e irá a la vanguardia para proclamarla» ${ }^{8}$.

Tras las elecciones, comenzó un proceso de revocación de medidas adoptadas en el primer bienio, se aceleró la polarización social y política y se inició una nueva etapa en la conflictividad social y la violencia. Los dirigentes socialistas vieron cortado definitivamente el camino legal hacia el socialismo: «estamos ... en un proceso fascista, y querer detenerlo parlamentariamente es dar tiempo y fuerza al enemigo». Se creó en todas las organizaciones obreras un sentimiento claro de que sus intereses estaban amenazados, en el que confluyeron la crisis económica; la supresión o paralización de las medidas sociales reformistas, defendidas hasta por quienes previamente las habían atacado, como el PCE; los sucesos internacionales, marcados por el desarrollo del fascismo; y la idea de amenaza autoritaria y/o fascista en España, elementos que expusieron todas las organizaciones en mítines y artículos de prensa. Esto favorecía la realización de una acción colectiva violenta, ya que creció la idea de que realizada ésta a tiempo se evitarían los costos de una represión que, de lo contrario, consideraban que iría en aumento. Pero, entre los socialistas, no había unanimidad en cuanto al paso siguiente a dar: La Comisión Ejecutiva de la UGT, presidida por Besteiro, no veía necesario realizar ningún tipo de acción violenta; Prieto planteaba profundizar los contenidos sociales de la República, su programa requería el apoyo de militares y republicanos, y la realización por los obreros de una huelga general pacífica, como en los movimientos de 1917 y 1930; Largo Caballero hablaba ambiguamente de revolución social, república socialista y dictadura del proletariado, en relación con el modelo insurreccional soviético de 1917 , que implicaba el apoyo de las masas y un plan revolucionario que incluía el control de los centros importantes de las principales ciudades, en especial de la capital, un ejército propio, la alianza con otras organizaciones obreras y el apoyo o neutralidad del ejército y fuerzas del orden. Frente a su idea de acción defensiva, las juventudes socialistas llegaron a defender una actuación claramente ofensiva: Renovación dijo que shabría de prometérsenos el poder por medios electorales y no aceptariamos ... el poder ha de venir a nuestras manos indefectiblemente por medios revolucionarios». En enero de 1934, se aprobó

8 La primera cita es de FPI, AH III-1, Actas Comité Nacional del PSOE, ff. 13-14; las demás, de Renovación, la primera, del $11 / 11 / 33$, p. 3; la segunda, del $9 / 12 / 33$, p. 1; la tercera, curiosa premonición de los sucesos de febrero en Austria, de su número del $6 / 1 / 34$, p. 4 ; la cuarta, del 9/12/33, p. 2; la valoración sobre Madrid, del $9 / 12 / 33$, p. 1, «Instantánea. Estampa electoral», Sobre el triunfo en los pueblos, ver Jutıরi, S., Madrid, 1931-1934..., op. cit., p. 267, nota a pie de página. Como a nivel estatal, la radicalización de la Federación Provincjal de Madrid de la FJS fue anterior a la de la Agrupación Socialista Madrileña: para llegar al socialismo «no hay más camino ... que la dictadura del proletariado. Y a eso vamos», escribió en diciembre de 1933 su secretario. La Federación comunicó a la Ejecutiva del PSOE que «con simpatía vemos el que se pueda realizar un frente único con trabajadores para llevar a cabo una acción revolucionaria, pero con profundo desagrado veríamos ... una nueva conjunción con republicanos» (Renovación, 2/12/33, p. 2, PINTADO, J, «نंAhora? Pues a tealizan; FPI, AH 62-57, Correspondencia CE PSOE-JSE Madrid, f. 3).

1Hicpania, LIX/3, núm 203 (1999) 1063-1 103 
el programa presentado por Prieto y se constituyó una Comisión Mixta, con representantes de las tres organizaciones socialistas, que debía preparar la insurrección. Hubo acuerdo en "cuando" actuar: cuando hubiese una provocación de las derechas, concretada en la llegada al poder de la CEDA. La acción quedaba, así, vinculada a una iniciativa del gobierno, buscando legitimarla y justificarla, pero ésto permitía a las autoridades preparar su capacidad represiva para hacetle frente, aumentando los costos de la acción y dificultando la movilización de recursos (definida como el control de ventajas que previamente no tienen los grupos)"

La FJS buscó influir en este debate a través de su órgano de prensa. En noviembre de 1933, atacó a los partidarios de Besteiro: había que reestructurar las organizaciones socialistas, ya que "hay hombres e ideas que estorban ... la marcha de la revolución ... los hombres del programa minimalistas. Tras una reunión conjunta de las ejecutivas del PSOE y la UGT, el 18 de diciembre, planteó que habia que luchar "por vencer toda orientación reformista» en éstas: «si no se retira buenamente, será preciso desarraigar con violencian. Tras la dimisión de los besteiristas, la FJS, cuya orientación izquierdista se vio refrendada en su V congreso, en abril de 1934, inició la lucha contra la postura de Prieto: Renovación pidió «la depuración del Partido»; «las Juventudes Socialistas no se batitán en la calle por conseguir una solución que ... tiene un carácter exclusivamente burgués». Ésto muestra la autonomía cada vez mayor de la organización juvenil con respecto al partido. Seguramente está relacionada con estos ataques al sector prietista la propuesta que Cabello presentó a la Ejecutiva del PSOE, el 11 de julio de 1934, para que «se llame la atención a los elementos dirigentes de la Federación de Juventudes Socialistas y ... a los que dirigen el periódico Renovación para que procuren guardar a todos los elementos del Partido el respeto y la consideración que se merecen», que fue aprobada ${ }^{10}$.

Aumentaron las justificaciones del uso de medios violentos y los llamamientos a la juventud para que los adoptase, importantes por su papel en la definición de una postura compartida por todos los miembros de la organización, necesaria para que del discurso se pase a la acción violenta. En este sentido, es

- La primera cita es de Leviatan, $\mathrm{n}^{\circ} 4$, (agosto 1934), "Glosas del mes», p. 8, la segunda se puede ver en Renovación, 9/9/34, p. 4, «Fijando posiciones: el P.S. ante unas posibles elecciones». Los partidarios de Besteiro dimitieron del Comité Nacional de la UGT en enero de 1934; también se retiraron de la dirección de la Agrupación Socialista Madrileña, donde se nombró una nueva dirección más acorde con la línea política marcada por Prieto y Largo Caballero, presidiòa por R. Henche, con Alvarez del Vayo de vicepresidente y M. Albar de secretario. La definición de movilización de recursos se puede ver en TiL.., C., From Mobilization ..., op. cit., pp. 54-55.

10 Renovación, la primera cita es del $25 / 11 / 33$, p. 4 ; las dos siguientes, del $23 / 12 / 33$, p. 4 . Sobre los ataques al sector prietista, ver Renovación, 7/7/34, p. 1, «Por la depuración del Partidon; la segunda cita, en el mismo número, p. 1, «Los equidistantes y la posición de las Juventudes Socialistas»; la propuesta de Cabelio, en FPI, AH II-1, Actas CE PSOE, 1934. La FJS defendía claramente su autonomía, rechazando que las Juventudes fueran «órganos secundarios» del PSOE (Renovacion, 25/11/33, p. 4, «Programas máximos. Socialismo o fascismo»). 
tan o más importante que en gran número de actos públicos y en la prensa de las organizaciones socialistas se recogiese la necesidad del uso de la violencia para defender las conquistas logradas y para avanzar hacia el socialismo, que el hecho de que Prieto hablase de revolución en el Congreso. En Renovación destaca la fecha relativamente temprana en que se iniciaron: ya en noviembre de 1933, J. Laín defendió la violencia revolucionaria: «al fascismo es preciso combatirlo en su terreno", "el de la violencia». Los socialistas mostraban, además, una gran confianza en sus posibilidades: Prieto dijo que «frente a estas falanges del Partido Socialista y de la Unión General de Trabajadores ... es imposible oponer nada en España); El Socialista rechazó la posibilidad de una derrota ${ }^{11}$.

Sin embargo, para el éxito de una acción insurreccional son importantes, también, las alianzas que se establezcan con otros grupos sociales u organizaciones políticas. Pero la unidad entre las organizaciones obreras era dificil, por la presencia de distintos proyectos políticos en general, y revolucionarios en concreto, con diferentes estrategias y objetivos. Aunque el 16 de diciembre se anunció la formación en Barcelona de la Alianza Obrera de Cataluña, para los socialistas, las Alianzas eran un medio pata paliar su falta de hegemonía en determinadas zonas, y frenaron su desarrollo, aunque aumentaron las tendencias unitarias en las organizaciones provinciales y locales y, seguramente por ello, hubo llamamientos a la unidad de la prensa y los dirigentes socialistas. La postura de la CNT dependió en gran parte del alcance de su división interna: las zonas cuyos miembros estaban más próximos al «treintismo» eran más proclives a la unidad de acción y, en marzo de 1934, se firmó el pacto de alianza asturiano. El PCE no aprobó su ingreso en las Alianzas hasta septiembre. Con su entrada, los socialistas consideraron el «frente único», identificado con las Alianzas Obreras, «virtualmente logrado», aún faltando la CNT: «toda la España Obreta ... está detrás de las Alianzasy. En la Alianza Obrera de Madrid, creada en torno a matzo de 1934, había tepresentantes del PSOE, FJS, Junta Administrativa de la Casa del Pueblo, Agrupación Sindicalista Libertaria e Izquierda Comunista. Poco después se incorporó la Federación Sindical Tabaquera ${ }^{12}$. Pero cada grupo manturvo gran parte de sus proposiciones anteriores, buscando que sus posturas fueran las aceptadas por los trabajadores, y faltaban los numerosos miembros de la $\mathrm{CNT}$, a lo que se sumaba la propia división entre los socialistas, con lo que cualquier acción verdaderamente coordinada se hacía prácticamente imposible.

Se inició también un debate entre las distintas organizaciones juveniles obreras sobre su unidad. En enero de 1934, Renovación hizo un llamamiento

11 LAín, J., «La dialéctica de la pistola», Renovación, 4/11/33, p. 3; PriEIO, I., «Discurso en el cine Pardiñas», Discursos fundamentales, Madrid, Tumer, 1975, p. 184; El Socialista, 18/9/34, p. 1 , «La consigna de hoy».

12 La cita en E/ Socialista, $13 / 9 / 34$, p. 3, «Virtualmente está ya logradon; la constitución de la Alianza Obrera de Madrid en Boletin de la Agrupación Socialista Madridleña, $2^{\circ}$. trimestre de 1934, p. 1; que habla de que se mantenían contactos desde marzo; MuNis, G., Jalones de derrota, promesas de victoria, Madrid, Zero, 1977, pp. 135-137, sitúa la creación de la Alianza Obrera de Madrid entre diciembre de 1933 y marzo de 1934.

Hi.pania, J.1X/3, núrn. 203 (1999) 1063-1103 
para «lograr un frente único juvenil ... entre socialistas, comunistas y sindicalistass, lo que también pidieron la Izquierda Juvenil Comunista (la organización juvenil de la Izquierda Comunista) y la UJCE (que se dirigió a la FJS y a las Juventudes Libertarias). A propuesta de la UJCE, se reunieron el 26 y 30 de julio de 1934 una delegación de ésta y otra de la FJS. En este debate se reflejaron las importantes diferencias que en cuanto a la misma definición de la situación española, a estrategias, tácticas y objetivos, había entre las dos organizaciones juveniles. Así, no hubo acuerdo en los objetivos que debía tener el frente único, ni, por tanto, en como organizarlo y con que aliados, en el papel de las luchas parciales y en cual debía ser el órgano dirigente de la revolución; sólo parecía haberse llegado a un acuerdo en el cese de los ataques mutuos y en el planteamiento, muy general, de que en las acciones concretas trabajarían juntos. El debate y la relación con las organizaciones juveniles del $\mathrm{BOC}$ e lzquierda Comunista eran planteados por la FJS de diferente forma: «si trotskistas y bloquistas ... vinieran a nuestro campo a ayudarnos a dar la batalla a la fracción reformista, los frutos serían más rápidos», dijo Renovación. Ya sea por su menor número, por unas posiciones parcialmente más cercanas, o porque no estaban implicados en organizaciones internacionales sólidas, veían factible una posible integración de éstos en las organizaciones socialistas ${ }^{13}$.

\section{LA CONFLICTIVIDAD MADRILEÑA ANTES DE OCTUBRE}

En Madrid, los primeros momentos de la República fueron, por la estructura industrial, las condiciones de trabajo y la postura de las organizaciones obreras, y a pesar del paro creciente, de relativa paz social, que no se rompió hasta avanzado 1933. Pero, tras las elecciones de 1933, lo que faltó a las masas de la UGT fue la protección que les daba la presencia de los socialistas en el gobierno. El sentimiento de abolición de las reformas y de «peligro» era grande, independientemente de su alcance efectivo. A esto se sumó el intento de la UGT de recuperat la iniciativa sindical y el que los meses posteriores a las elecciones fueran también los de mayor desempleo. Así, se inició una nueva fase en la conflictividad laboral madrileña y el número de huelgas se disparó: mientras en 1933 hubo 27, en el primer semestre de 1934 se contabilizaban ya 37 . Se desarrollaron las huelgas generales de industria: destacaron las de camareros, la segunda huelga de la construcción y la de metalúrgicos. Afectaron a sectores amplios, lo que hizo más dificil llegar a acuerdos y aumentó su duración; cam-

13 El llamamiento de la FJS está recogido en Renovación, 21/7/34, p. 1, «Los jóvenes socialistas ante el fascismo"; el de la UJCE, en Renovación, 27/1/34, p. 4; la postura de la Izquierda Juvenil Comunista, en Renovación, 27/1/34, p. 4, y 3/3/34, p. 3. Las actas de las reuniones entre la FJS y la UJCE están publicadas en VIÑAS, R., La formación de las Juventudes Socialistas Unificadas (1934-1936), Madrid, Siglo XXI, 1978, pp. 71-109. Renovación informó que tras estas reuniones, muchas secciones de la UJCE habian ingresado en la FJS, citando, de Mtadrid, las de Móstoles, Ciempozuelos, El Pardo y Morata de Tajuña (Renoyación, 25/8/34, p. 1). Sobre las ottas organizaciones juveniles, ver Renovación, 1/9/34, p. 1, «Por la depuración revolucionatia del Partido».

Hitpania, LLX/3, núm 203 (1999) 1063-1103 
biaron, también, las formas en que se organizaban: el comité sindical dejó paso a los comités de huelga y a las asambleas. Los trabajadores de industria lograron con estas acciones, en palabras de S. Juliá, "sus mayores y más amplias conquistas", tanto con relación a los contratos conseguidos, como uen el plano de su capacidad organizativa, de su unidad sindical, y de su resistencia». Pero la unidad de acción entre los sindicatos no se mantuvo, y mostró la falta de una política clara y coordinada de alianza en las organizaciones socialistas: mientras colaboraban con la CNT, trabajaban con los grupos comunistas heterodoxos y se reunían con el PCE. Además, iniciada la preparación del movimiento insurreccional, la UGT buscó cortar las huelgas de industria: C. Hernández Zancajo informó que la Casa del Pueblo de Madrid «está haciendo todo lo posible por reducir las huelgas declaradas y las que están próximas a declararses ${ }^{14}$.

Pero la conflictividad antes de octubre se caracteriza principalmente por una tendencia creciente a la acción violenta. El desarrollo de las organizaciones fascistas promovió el enfrentamiento en la calle entre las juventudes obreras y las falangistas, lo que favoreció la unidad de acción de las primeras, principalmente en la primavera de 1934. La violencia adoptó dos formas: enfrentamientos con las fuerzas del orden y acciones entre grupos rivales, lo que muestra que los grupos situados fuera del poder gubernamental pueden reprimirse mutuamente, modificando los costes recíprocos de su acción colectiva. Desde el 1 de enero al 25 de agosto de 1934, los detenidos de carácter social y político menores de 21 años fueron 470 . Hubo 31 heridos (8 de Falange, uno de Acción Popular, 5 de organizaciones socialistas y 17 sin filiación clara) y 13 muertos ( 4 de Falange, uno de Acción Popular, 2 de organizaciones socialistas y 6 de los que no consta filiación), con edades comprendidas entre los 15 y los 24 años. Al menos 8 de los heridos y 5 de los muertos eran estudiantes: los incidentes violentos en institutos y en la Universidad de Madrid entre miembros del SEU y de la FUE eran frecuentes. El aumento de este tipo de enfrentamientos hizo que el Gobierno limitase la participación de la juventud en las organizaciones políticas mediante un decreto del 28 de agosto ${ }^{15}$.

14 La cifra de huelgas en 1933 está tomada de Julí́, S., Madrid 1931-1934 ..., op. cit.; la de 1934, de TuÑón de LARA, M. (Dir.), Historia de España. 9. La crisis del Estado: Dictadura, Repriblica, Guerra (1923-1939), Barcelona, Labor, 1988, p. 181. Para el desarrollo de las huelgas ver JuLí, S., Madrid, 1931-1934 ..., op. cit., passim, las citas, en pp. 409-410; la información de Hernández, en FPI, AARD, XIX, Actas Comité Ejecutivo de la UGT, 1934, 8/3/34, pp. 36-37.

${ }_{15}$ El decreto está recogido en El Debate $22 / 8 / 34$, p. 2 y en E/ Solde misma fecha, p. 4. Prohibia la militancia política a menores de 16 años, $y$ a los que tuvieran menos de 23 sin el consentimiento de sus padres. Los datos son una elaboración propia a partir de las estadísticas que introduce el decreto. Como han situado algunos teóricos sociales, la juventud es, en muclios aspectos, una caja de resonancia del cambio social y refleja, en una forma más dramática, las luchas que se producen en la sociedad, por lo que los movimientos juveniles suelen cobrar fuerza en épocas de crisis y cambio social y político (Ver, por ejemplo, BRAUNGIIART, R.G., «Historical Generations and Youth Movements: A Theoretical Perspectiven, Research in Social Movements, Conflict and Change, vol. VI (1984), pp. 95-142).

Ilípuniu, LIX/3, núm. 203 (1999) 1063-1103 
La reacción de las organizaciones obreras se desarrolló también contra la CEDA y dio lugar a la primera huelga general política del Madrid republicano, el 22 de abril de 1934, como respuesta a la concentración de la Juventud de Acción Popular en El Escorial. Ya desde el día 20 se produjeron movilizaciones de protesta convocadas por las organizaciones juveniles socialistas y comunistas, aunque sin coordinarse entre ellas: numerosos grupos de obreros se concentraron el 20 en torno al eje Alcalá-Paseo del Prado, en la Puerta del Sol y en barrios periféricos como Puente de Vallecas y Cuatro Caminos, produciéndose enfrentamientos con miembros de Acción Popular y con las fuerzas de orden público, algunos de ellos claramente organizados, que continuaron el 21. En Aranjuez, se volcaron dos autocamiones que conducían a miembros de Acción Popular. La huelga de 24 horas fue convocada por la FJS, que hizo circular una octavilla el 21, llamando a una shuelga antifascistas. Peto la acción era apoyada por más organizaciones: la Comisión Ejecutiva de la UGT había rechazado una propuesta de la Federación Local de Obreros en Madera de Madrid para que la UGT declarase «una huelga general de 24 o 48 horas», con el objetivo de que el gobierno suspendiera la «marcha fascistas. También la UJCE y el PCE se habían planteado realizar acciones de protesta y, según Munis, la Izquierda Comunista lo propuso a la Alianza Obrera de Madrid, pero los socialistas no aceptaron hasta el 21 de abril declarar la huelga. El texto de la octavilla, que la justifica porque «el gobierno Lerroux no se ha limitado a autorizar y proteger la manifestación» japista, sino que «ha utilizado la fuerza pública ... contra los trabajadores", haciendo referencia a los sucesos de los dís anteriores, parece apoyar esta versión. En Aranjuez, se convocó una huelga general de 48 horas, como protesta por la represión del día $21^{16}$.

El 22 de abril, la actividad de la ciudad se paralizó totalmente desde la una de la madrugada. Se movilizó a las fuerzas de seguridad para mantener el orden y los servicios esenciales: los soldados de infantería se encargaron de la vigilancia y los servicios de intendencia fabricaron pan. Durante la jornada, se produjeron numerosos enfrentamientos violentos, claramente organizados, al menos desde las Juventudes Socialistas: según Tagüeña, las milicias socialistas actuaron, por primera vez, «desempeñando misiones» en esta huelga; uno de los procesados por los sucesos de octubre declaró que «fue requerido en la Casa del Pueblo ... para que se hiciera cargo de una pistolas. Hubo numerosos tiroteos entre guardias de asalto y manifestantes, se lanzaron algunas bombas y se atacaron varios autobuses que transportaban participantes en la concentración; en Tetúan de las Victorias fueron asaltadas dos iglesias (muestra del mantenimiento marginal de las acciones colectivas tradicionales). A las doce de la noche, las Juventudes Socialistas repartieron dos manifiestos

16 Los sucesos del 20 y del 21 están recogidos en E/ Socialista, 22/4/34, p. 4 (como sucederá tambjén en la siguiente huelga general política, se publicó normalmente); la propuesta de la Federación de Madera, una de las más importantes de la UGT de Madrid, en FPI, AARD, XIX, Actas Comité Ejecutivo de la UGT, 1934, p. 67; MuNIs, G., Jalones de derrota.., op. cit., p. 140 ; la convocatoria, en El Socialista, 22/4/34, p. 6. 
en los que se «ordenabas la vuelta al trabajo y se planteaba que la huelga había mostrado la fuerza de los trabajadores: «los obreros deberán envainar sus armas ... hasta que las requiramos para empresas más definitivas». E/ Socialista destacó la «disciplina» en el cumplimiento del paro, que «daba una idea bien exacta de lo que pueden dar de sí las posibilidades proletarias para un movimiento a fondo contra la reacción españolas ${ }^{17}$.

El 29 de agosto murió, en un enfrentamiento con falangistas, J. de Grado, miembro del Comité Central de la UJCE. Su entierro, el 31 de agosto, supuso un hito importante en el acercamien to entre las organizaciones juveniles: se realizó un comunicado conjunto llamando a asistir al sepelio, firmado, entre otras organizaciones (la mayoría sindicatos de oficio), por la UJCE, la Juventud Socialista Madrileña y las Juventudes Libertarias, que formaron un comité para organizar el acto, como homenaje, no sólo a Grado, sino también a J. Rico y otros militantes obreros asesinados. También la Junta Administrativa de la Casa del Pueblo convocó a los trabajadores al entierro. El acto en sí destaca por su gran contenido simbólico, cuidadosamente preparado. Una manifestación salió de la plaza de Manuel Becerra: «las milicias socialistas y comunistas, de uniforme, con sus secciones femeninas", se colocaron a la cabeza, seguidas por el féretro "cubierto con la bandera de la sociedad de Escultores-Decoradores», a la que pertenecía Grado, llevado por socialistas y comunistas. En la cabecera de la manifestación había «diputados socialistas, representantes de "El Socialista» y "Mundo Obrero», delegados de las organizaciones socialistas y comunistas y dirigentes de ambas». Tras el entierro, tomaron la palabra Trifón Medrano, Pasionaria y E. Puente (presidente de la Juventud Socialista Madrileña), que destacaron la unidad lograda. El Socialista calificó el acto como «jornada grandiosa del proletariado madrileño», y Mundo Obrero pidió «limpiar ... de obstáculos el camino para llegar a la victorias ${ }^{18}$.

17 TAgüeñ, M., Testimonio de dos guerras, México, Oasis, 1973, p. 61; Ia declaración procede de «Causa que se instruye en esta plaza por el supuesto delito de rebelión militar contra los dirigentes de las llamadas milicias socialistas», Archivo General de la Guerta Civil Española (AGGC, anterior sección Guerra Civil del Archivo Histótico Nacional), Salamanca, Sección Militar (SM), carpetas 343, 344, 345, 346 y 347, la cita en la 343, f. 499 (verso); para los datos sobre la huelga, ver E/ Socialista, 24/4/34, p. 2, que reptoduce las dos octavillas de las Juventudes Socialistas; su valoración, en p. 1.

18 El 10 de junio habian sido asesinados por falangistas tres jóvenes socialistas $0 . \mathrm{y} \mathrm{L}$. Rico y M. Jiménez Arroyo). Las citas sobre la organización del acto proceden de El Socialista, $1 / 9 / 34$, p. 1 . Ver también Nit.Kr.N, M., ${ }_{2}$ Porqué bicimos la revolucián?, Barcelona, Ediciones Sociales Internacionales, 1936, p. 119-120; la valoración de Mundo Obrero, en su número del $1 / 9 / 34$, p. 1 . Se destaca su contenido simbólico porque aencontrar símbolos que sean suficientemente familiares para movilizar a la gente alrededor de ellos es una de las mayores tareas de una organización para el movimiento», ya que «os movimientos construyen su acción colectiva en torno a símbolos culturales" (Tarrow, S., Power in Movement, op. cit, p. 119). El papel de los elementos simbólicos y culturales se destaca cada vez más en el estudio de los movimientos sociales, como sitúa Cruz, R., (La cultura regresa ...), op. cit, passim.

Ijipania, JIX/3, núm. 203 (1999) 1063-1103 
La siguiente huelga general política se produjo el 8 de septiembre, como protesta por la Asamblea del Instituto Agrícola catalán de San Isidro. Fue un paso más en la unidad de las organizaciones obreras, y otra muestra de que, en el desarrollo de ésta, las organizaciones locales madrileñas fueron por delante de sus respectivas direcciones nacionales: la huelga fue decidida en una reunión celebrada el día 7 por las directivas de todos los sindicatos obreros afectos a la UGT y al PCE, y la Ejecutiva nacional de la UGT no tenía un conocimiento previo de su convocatoria. Ésta fue firmada por «los Partidos, Organizaciones y Juventudes proletarias de Madrid» y se vinculó a la del 22 de abril: «todo es uno y lo mismo: ofensiva contra la clase obrera, la única que está dispuesta a impedir que el fascismo se adueñe del Podens. La huelga se inició a las seis de la madrugada; a las ocho, el Ministerio de Gobernación pidió la ayuda del «pueblo de Madrid" para "poner término a la subversión y restablecer el orden y la disciplinas, lo que se puede considerar una estrategia de coacción del Estado «de definición», que implica intentar movilizar «a la opinión pública contra personas y grupos considerados políticamente peligrosos». Y es que desde los órganos de poder no se vio como una huelga más: se habló de rebeldes, revoltosos, ... Se publicaron El Debate, ABC, Ahora, Siglo Futuro y La Época, que fueron vendidos por miembros de «las organizaciones juveniles de derechas». El metro no funcionó y los pocos tranvías que lo hicieron fueron "conducidos por soldados y guardias de asalto", que también prestaron servicio en la estación del Norte. Los pocos cometcios que habían abierto fueron cerrando al irse conociendo la convocatoria. El gobierno y las organizaciones pattonales se acusaron mutuamente de favorecer con su «negligencia» el éxito del paro: Salazar Alonso se reunió con la dirección del Bloque Patronal, la Cámara de Industria y el Círculo Mercantil, ordenándoles que abriesen sus establecimientos porque «no dan espiritu de ciudadanía cetrando precipitadamentes. Por la mañana, se clausuraron la Casa del Pueblo de Madrid, las oficinas de la UGT y los locales de la CNT y del PCE, y se ordenó la detención de sus dirigentes; por la noche, el resto de los centros obreros de la provincia. A primera hora de la tarde se acuartelaron las tropas y se prohibió la formación de grupos en las calles a partir de las ocho de la noche ${ }^{19}$.

Los incidentes violentos fueron abundantes. Hubo 6 muertos y 40 heridos y los detenidos fueron cerca de 400 (la mayoría, jóvenes). Por el objetivo de la acción, destacan los enfrentamientos con los participantes en la Asamblea de

19 El desarrolio de la huelga se recoge en $E /$ Debate, $9 / 9 / 34$, pp. 1 a $3 ; E / S o l, 9 / 9 / 34$, pp. 1 y 8; El Socialista, $9 / 9 / 34$, p. 1 ; $A B C, 9 / 9 / 34$, pp. 35-41, Mundo Obrero, 10/9/34, pp. 1,3 y 4; la falta de conocimiento de la dirección de la UGT, en FPI, AARD, XIX, Actas Comité Ejecutivo de la UGT, 1934, p. 173, reunión del 13/9/34. La convocatoria está recogida en Mundo Obrero, 10/9/34, p. 1. Sobre las estrategias de definición, ver WAIDMANN, P., «Estrategias estatales de coacción", Sistema, ${ }^{\circ}$. 65, (marzo 1985), p. 94. Parte de la «ineficacian del gobierno en paliar los efectos de estas huelgas se debía a la novedad del uso de éstas para intentar impedir la realización de actos de otras organizaciones, lo que se refleja en el hecho de que la incapacidad fue mayor en la louelga del 22 de abril que en ésta (lo que se destacó en los periódicos).

IHipganiu, LIX/3, núm. 203 (1999) 1063-1103 
los agrarios. Pero los sucesos violentos a cuenta del éxito de la huelga en sí, como paralización de la ciudad, fueron los más abundantes, principalmente los apedreamientos y tiroteos a tiendas y servicios de transporte público. Ambos tipos de acciones produjeron numerosos enfrentamientos con las fuerzas del orden. Fuera de la capital, hubo un tiroteo importante en Catabanchel Bajo, al intentar grupos de obreros paralizar los tranvías. Parte de estas acciones parecen tener un carácter organizado, lo que muestra que «la violencia colectiva surge de la acción colectiva premeditada ..., de la que es simplemente una extensión táctica o estratégicas. Las organizaciones convocantes elaboraron un manifiesto que ordenaba la vueita al trabajo a las doce de la noche, y hacían saber «que estamos dispuestos a realizar aquellas acciones que sean necesarias para lograr por la fuerza de la razón o por la razón de nuestra fuerza la liberación de los detenidos y la apertura de los centros obreros». Para estas organizaciones, el éxito de la huelga mostró nuevamente las ventajas de una acción colectiva conjunta y les hizo creer más en sus posibilidades de victoria: Renovación lo consideró un ejemplo de que la «salvación» de los trabajadores «está en la unidad de acción lealmente practicadas; Mundo Obrero relacionó también el éxito con la unidad y destacó la «activa participación de los jóvenes socialistas y comunistass ${ }^{20}$.

La unidad de acción de las organizaciones madrileñas tuvo su culminación en el acto conjunto de las Juventudes Socialistas y Comunistas de Madrid, realizado contra el decteto sobre la participación de los jóvenes en la política, y celebrado en el «Stadium» el 14 de septiembre de 1934. Los oradores, designados por acuerdo de ambas organizaciones, muestran la importancia dada al acto: intervinieron, por las Juventudes Socialistas, S. Carrillo; por las Comunistas, T. Medrano; por el PSOE, M. Albar y J. Bugeda, y por el PCE, J. Hernández. E/ Socialista lo consideró un «verdadero mitin de unidad proletaria» y habló de 80.000 asistentes; Mundo Obrero, de más de 90.000. La escenografia fue cuidadosamente preparada: E/ Socialista dijo que «las milicias socialistas y comunistas evolucionaron [desfilando «militarmente»] para situarse en el centro del campo ["frente por frente ... en perfecta formación militar»]), "en la presidencia fue colocado un gran retrato de Thaelmann', y se cantaron la Internacional y los himnos de ambas juventudes. En todas las intervenciones se habló de la necesidad de que las organizaciones obreras tomasen el poder, con una gran confianza en un éxito no lejano, y se criticó la situación de la República. Carrillo dijo que «si este gobierno ... no rectifica, serán estas Juventudes las que asalten el Poden); J. Bugeda señaló que "nadie nos garantiza nuestros derechos ... Y no nos queda más que un camino: el de la violenciay; J. Hernández hizo un nuevo llamamiento a los anarquistas para que se uniesen a ellos. Al concluir las inter-

20 Las cifras están tomadas de E/Sol,11/9/34, p. 4. Según E/Debate, $9 / 9 / 34$, p. 3, se produjeron 6 muertos y 46 heridos. La cita sobre la violencia, es de $A Y A, R$., «Reconsideración de las teorias de la revolución', Zona Abierta, Madrid, n ${ }^{\circ} .36-37$ (julio-diciembre 1985), p. 24. El manifiesto se puede ver en $E / S o l, 9 / 9 / 34$, p. 8; las valoraciones, en Mundo Obrero, 10/9/34, p. 4, y Renovación, 14/9/34, p. 4.

Hi.pania, J.IX/3, núm. 203 (1999) 1063-1103 
venciones, «se sucedieron los desfiles de los milicianos uniformados». Este mitin fue el último acto de las organizaciones obreras madrileñas antes de los sucesos de octubre, y la masiva asistencia aumentó la confranza de las organizaciones socialistas en el triunfo de una acción insurreccional ${ }^{21}$.

\section{LA MOVUIZACIÓN DE RECURSOS}

Se daban, por tanto, las condiciones para un conflicto social violento: conciencia de desigualdad e injusticia; obstáculos infranqueables o percibidos como tales para conseguir mejoras; represión creciente del aparato estatal; perspectiva generalizada de que se logrará la victoria; existencia de cierto grado de solidaridad de los grupos participantes e incapacidad o falta de voluntad de los gobernantes de lograr una solución consensuada. Pero las oportunidades que animan el inicio de una protesta no tienen porqué permitir su éxito, que en parte depende de la movilización y acumulación de recursos que se realice. Los socialistas, además de concienciar a sus bases con los llamamientos a la violencia y a la revolución y las críticas a la situación de la República para formar un consenso sobre los acontecimientos, los actores y la acción a realizar, movilizaron su estructura organizativa y sus recursos materiales para "preparar la revoluciómo. Estos preparativos se concretaron en la creación de milicias, a modo de "ejército» revolucionario, lo que requería también la obtención de armas, y en buscar el apoyo de miembros de los cuerpos armados 22.

La creación de las milicias no hubiera sido posible sin la participación de la juventud. En febrero de 1934, el Comité Nacional de la FJS envió una circular a sus federaciones en la que ordenaba "que en un plazo muy perentorio ... organicen las milicias juveniles", buscaran medios de armarse y controlaran a los "enemigos», y quedaron vinculadas al movimiento revolucionario como «organización para la acción colectiva). Según las instrucciones enviadas a las organizaciones socialistas, las Juntas provinciales, creadas para la preparación del

21 El 6 de septiembre habia habido una manifestación contra el decreto en Carabanchel Bajo, organizada conjuntamente por las juventudes socialistas y comunistas (Mundo Obrero, $7 / 9 / 34$, p. 4). La designación de los oradores se recoge en E/ Socialista, 12/9/34, p. 1; la información sobre el mitin está tomada de El Socialista, 15/9/1934, p. 4, y 16/9/34, p. 1, ver también Mundo Obrero $15 / 9 / 34$, pp. 1-2 y El Sol, $15 / 9 / 34$, p. 8. Para las valoraciones, ver El Socialista, $16 / 9 / 34$, p. 1 ; Mundo Obrero $15 / 9 / 34$, p. 1 ; Renowación, $22 / 9 / 34$, pp. 2 y 3.

22 Las condiciones para un conflicto violento en SOIELO, I., "Violencia y modernidad", Madrid, Claves, n. 1 (abril 1990), p. 52; sobre el concepto de formación del consenso ver Cruz, R., «La cultura regresa ...», op. cit., p. 32. Renovación, ya en diciembre de 1933, situó que «la preparación revolucionaria que se nos pide» es «la preparación materal para una insurrección violenta y armada); (militarización de los cuadros de choque; disciplina autoritatia de arriba a abajo; armamento» (Renoyación, $9 / 12 / 33$, p. 2, (Ĺa preparación revolucionaria que se nos pide»). Largo Caballero se lo "recordós en la clausura del V Congreso juvenil (ver LARGo CABALLERO, F., Discurso pronunciado en la sesión de clausura del V Congreso de las Juventudes Socialistas de España, (20 de abril de 1934), Bilbao, Tallezes Gráficos Fermín Zarza, s.f., p. 15).

Hispaniu, LIX/3, núm. 203 (1999) 1063-1103 
movimiento, debian ser las encargadas de organizar milicias o "grupos de acción' de 10 hombres, con un jefe y un subjefe, que serían complementadas por "grupos técnicos», especializados en determinados campos como los de gas, telégrafos, o electricidad. Reproducían, por tanto, la estructura del ejército. Renovación asumió un papel de canal de transmisión de instrucciones para su formación, como refleja la publicación del «Decálogo del joven socialista», que reproducía la organización de las milicias. Según S. Juliá, el fracaso de octubre de 1934 fue «resultado de la inadecuación más absoluta entre el objetivo de la toma de poder por la vía insurreccional, la estrategia elaborada para conseguirlo y el instrumento de la acción propuesto: la organización obrera sindical-societariay; pero el instrumento no eran los sindicatos. Las instrucciones distinguían el movimiento sindical que haría la huelga general, y el revolucionario, que debía encargarse de la insurrección y actuar contra «la fuerza pública». Por tanto, las características de la organización sindical influirían indirectamente, en función de que determinaban las experiencias previas y la identidad colectiva de los participantes ${ }^{23}$.

Toda acción revolucionatia requiere un proyecto insurreccional. Pero las instrucciones enviadas por los socialistas a sus organizaciones no pasaron de ser unos consejos prácticos aplicables a cualquier lugar, y no ilegó a existir un plan insurteccional coherente y único. En este tema, jugó también un papel importante Renovación, que publicó, en febrero de 1934, textos del libro La insurrección armada, de $A$. Neuberg indicando que «las Juventudes Socialistas deben leerlos, estudiarlos, comentarlos y adaptarlos a sus características locales». Los textos se conforman como consejos prácticos sobre el combate callejeto en las ciudades, y los veremos aplicado casi textualmente en las instrucciones enviadas: se debía tener un conocimiento exacto de la estructura de la ciudad, sus sistemas de comunicaciones, redes telegráficas y telefónicas, distribución de agua y electricidad; localización de partidos, periódicos, imprentas, instituciones económicas y gubernamentales, fuerzas armadas, etc. Defendía como estrategia la realización de «insurrecciones en los batrios, con diversiones simultáneas en los demás ...; luego, ataque general y concéntrico de los barrios centrales». Durante el combate, había que destruir las vías de comunicación de

23 S. Tarrow distingue entre "organizaciones formales», entendidas como aquellas organizaciones complejas que identifican sus fines con los de un movimiento o contramovimiento social e intentan llevarlos a cabo, y «organizaciones para la acción colectiva», formaciones temporales de activistas que llevan a cabo las confrontaciones con los antagonistas, es decit, creadas especialmente para la acción (TArrow, S., Power in Movement, op. cit., pp. 135-136). La orden de la FJS está recogida en Archivo Histórico Nacional (AHN), Fondos Tribunal Supremo, Reservados, Expediente 53, Largo Caballero, f. 174; las instrucciones, en LARGo CABALLIIRo, F., Escritos de la Repuiblica. Notas histónicas de la guerra en España (1917-1940), Madrid, Editorial Pablo Iglesias, 1985, 307 pp. 106 y ss; el decálogo en Renovación, 17/2/34, p. 1; la cita de JuLIA, S., en su "Introducción" a Largo CABMILLIRo, Escritos de la ..., op. cit., LV. Sobre los sindicatos, se puede ver también Renovación, 23/12/33, p. 3, «Más actual que nunca. La misión de los sindicatos\%.

Ifipania, LIX/3, núm. 203 (1999) 1063-1103 
los enemigos, desarmar a los soldados, organizar motines en la tropa y difundir «informes favorables a los insurgentes» ${ }^{24}$.

En abril de 1934, Madrid informó que su Comité revolucionario estaba formado por R. Henche, M. Albar y E. Puente; tenían «unas 60.000 pesetas», "para comprar armas", y los afiliados con que contaban eran en la "capital, $700 \mathrm{y}$ muchos en $\mathrm{Zd}, \mathrm{Ae}, \mathrm{Be}, \mathrm{Ce}, \mathrm{De} . .$.$) ; las armas y municiones eran «abundantes». So-$ bre el movimiento sindical, indicaba que "se controla», pero «la organización es deficiente, excepto en transportes». Según Largo Caballero, este comité era el encargado de organizar las milicias en Madrid, «pero no se hacía nada». Por ésto, se realizó una reunión con «los directivos de todos los Grupos Socialistas y sindicales», en la que se decidió que se encargara el propio Largo, que «reclamó la cooperación' de Puente, L. Menéndez y F. de Rosa. A. Rosal pensaba que el jefe de las milicias era Largo Caballero, lo que era una creencia extendida entre los milicianos procesados en Madrid. Se dividió la organización de la capital en cinco sectores o distritos. Según F. de Rosa y Rosal, el primero era mandado por J. Laín (le correspondían los distritos de Universidad y Palacio); el segundo, por F. de Rosa (distritos de Buenavista y Chamberí, incluyendo Cuatro Caminos, Chamartín y Ventas); el tercero, por Rosal (Centro y Hospicio); el cuarto, por Menoyo (Congreso y Hospital), y el quinto, por Victoriano Marco (Latina e Inclusa). El tercer sector se unió al cuarto sunos quince días antes del movimiento y en vista de que sólo se habian reunido ... unos 120 hombres», según Rosal. La otganización general de cada distrito la describió A. Escudero: se estructuraban en compañías de infantería y secciones de ametralladoras, dependiendo su número del de miembros de cada sector; «las compañías de infantería estaban integradas por un jefe de compañía y jefes de sección integradas cada una de ellas por tres escuadras ..., de a 10 hombres cada una, entre los que había un jefe y un sub-jefe»; en cada compañía shabía una escuadra llamada de enlace destinada a transmitir órdenes a sus secciones», y una sección de «Servicios Especiales», cuya misión era «llevar nota detallada» de los establecimientos del distrito ${ }^{25}$. Por las declaraciones de los detenidos, parece que esta organización no se completó prácticamente en ninguno de los sectores y sólo se logró una estructura mínimamente sólida en los dos primeros, que serán también los que más actúen.

24 Ver Renovación, $10 / 2 / 34$, p. 3 y $17 / 2 / 34$, p. 2 , «La insurrección armada». El libro es una obra colectiva de varios especialistas políticos y militares (Togliatti, Ho-Chi-Min, ...), publicado bajo el seudónimo de $A$. Neuberg, cuya primera edición española es de Madrid, Editorial Roja, 1932.

25 Largo Caballero, F., Escritos de ..., op. cit., el informe en p. 125; la organización de las milicias en p. 140. Sobre la dirección de Caballero, ver RosAL, A. del, 1934. El movimiento revolucionario de octubre, Madrid, Akal, 1983, p. 208; AGGC, SM, carpeta 343, declaración de J.M. Puig Guardiola, f. 84 recto, y F. Lafin Drunn, f. 297 verso. Sobre la organización y los jefes de las milicias, ver AGGC, SM 343, declaración de A. Escudero Mota, ff. 4 y 5; de F. de Rosa, f. 22 verso; de Rosal, f. 33 verso y 408 recto. Según Escudero, el tercer sector era mandado por E. Puente y el cuarto, por Rosal. 
En el primer sector había cinco compañias de infantería, cuyos jefes eran $\mathrm{E}$. de la Figuera, N. Gil Casado, R. Pérez, J. Muñoz Rodríguez y J.M. Puig Guardiola; y dos secciones de ametralladoras, dirigidas por Escudero y V. Gálvez; el jefe de la sección de servicios especiales era J. Juliá Garijo. Habia también una "sección de «Automovilismo", dirigida por S. Álvarez, «que contaba con diez conductores», todos trabajadores del "parque de automóviles del Ayuntamientom. Ésto fue confirmado por los acusados, que dijeron haber sido nombrados en sus cargos por Laín. El segundo sector, según F. de Rosa, estaba formado por cuatro compañías de 100 hombres, con tres secciones cada una, «de tres escuadras y una escuadra de mando"; además, tenía eun grupo de unos seiscientos hombres sin organizan", y una sección de servicios especiales. J. Setien declaró que los jefes de compañía eran I. Carmona, M. Tagüeña, «un tal Simón", S. Pérez, L. Simarro, F. Coello y F. Garrigos, y el jefe de la sección de ametralladoras, «un tal Mayordomo», lo que fue ratificado por los que fueron detenidos. Sobre el cuarto sector (en un primer momento el quinto), F. Martínez Martín declaró que «sus jefes de compañia etan Palacios, Luis Meneses..., un tal Emilio [Ruiz de Alejos] ..., él mismo, y J. Ruiz Suárez» ${ }^{26}$.

Teniendo en cuenta los milicianos de los que disponemos de sus nombres y los datos que dan los que indicaron el número de miembros de su sección o compañia resultan 566 (dejando aparte los 600 hombres sin encuadrar que decía tener de Rosa). Es una cifra cercana a los 700 de que hablaba el informe citado y muy baja, incluso, para la militancia del PSOE. Pero la información es escasa sobre dos de los cuatro sectores, por lo que su número podría acercarse a los mil hombres. Los 54 miembros de las milicias procesados en el sumario analizado eran hombres, y casi todas las mujeres implicadas fueron detenidas por guardar armas o haberles dejado reunirse en sus casas, lo que parece la aplicación de una propuesta de usar mujeres y niños para "trabajos fáciles" que venía en los textos de Neuberg. La media de edad era de $28^{\prime} 7$ años, es decir, era una organización moderadamente joven, lo que se refleja más en su distribución por edades: hay 32 personas que tenían entre 18 y 29 años, 16 , entre 30 y 40 , y sólo cinco, entre 41 y 50 . Su origen geográfico muestra la importante inmigración que recibió Madrid: aunque 19 eran madrileños, había una representación de la mayoría de las regiones españolas de tradición migratoria: 10 castellanoleoneses, cuatro de la actual Castilla-La Mancha, cinco andaluces, un extreme-

26. Ver AGGC, SM, 343, declaraciones de Escudero, f. 5 recto y f. 9 verso; de Juliá, f. 121 verso; de Guardiola, f. 84 verso; de Muñoz, f. 26; de Nouvillas, f. 118; de Álvarez, f. 178 verso; de Figuera, f. 11; de F. de Rosa, f. 22 verso y 23 recto (y declaración voluntaria ante policía en AGGC, PS MADRID 1918, f. 54); de J. Setien, f. 229-231; de I. Carmona, ff. 232 y 242; de Coello, f. 233 recto. F. Lafin dio los mismos nombres de jefes del segundo sector (f. 297 recto). J. Molina Clemente dijo que había sido jefe de escuadra, pero que dejó de serlo y era sólo un eafiliadon, lo que muestra la mentalidad sindical que mantenian algunos miembros de las milicias (f. 307 recto). La declaración de F. Martinez en f. 545 recto. Ver también declaración de Ruiz Suárez, en ff. 545-546 y de Ruiz de Alejos, que se dio de baja en la Guardia Civil en septiembre de 1934, en f. 554 recto. Todos citaron como jefe del sector a Victoriano Marco.

Hitpania, LIX/3, núm. 203 (1999) 1063-1103 
ño, dos gallegos, ... Fueron procesados también tres extranjeros, dos procedentes de regímenes fascistas (un alemán y un italiano), lo que muestra la especial preocupación de estos exiliados hacia los «peligros» fascistas o autoritarios y las relaciones entre las organizaciones antifascistas, en sentido amplio, de diferentes países europeos. En cuanto a las características socio-profesionales, ya Rosal destacó a las Juventudes Socialistas de Madrid, estudiantes, grupos de artes blancas, transporte, banca, oficinas, comercio y ferroviarios, lo que en gran medida se confirma por los datos de los procesados: había siete «choferes»; seis estudiantes (otros, como Laín, huyeron); cuatro empleados de banco (Marco y Menoyo, que no fueron detenidos, también lo eran), tres agentes comerciales y cuatro panaderos, frente a sólo tres jornaleros, un albañil o dos pintores. Están muy poco representados los sindicatos que constituían la ugran masa» de la UGT en Madrid: metalurgia, madera, camareros y construcción. A ésto haría referencia la información sobre el movimiento sindical citada, en la que se planteaba que era precisamente en transportes donde había una mejor organización. Sí guardaría relación con la composición del PSOE madrileño, formado principalmente por empleados, funcionarios y miembros de profesiones liberales, lo que sería otro indicio de que la insurrección no se dejó en manos de la organización sindical, a la que se reservó para la huelga general ${ }^{27}$.

Según Rosal, los centros de reclutamiento y de instrucción eran locales del PSOE y la UGT, como la Casa del Pueblo y los Círculos Socialistas. Pero, como se ve en las declaraciones, clausurados los centros socialistas, cualquier sitio pasó a ser válido para reunirse: Escudero declaró que normalmente se reunían en bares o cafés, cada sector por separado; N. Revruelto dijo que se teunían dos veces por semana y, por clausurarse el Círculo Socialista del Oeste, «lo hacian en la calle de Alberto Aguilerass. Según M.E. Ogier, J. Laín y F. de Rosa se reunieron en su casa varias veces. Rosal también contó que el adiestramiento lo realizaba G. Vidal, Teniente de Artillería, «sábados y domingos ..., en Madrid y sus alrededores, aprovechando excursiones a la sierras. Renovación parecía referirse a una de estas jornadas cuando recogió un «acto de propaganda» de la Federación Provincial de Madrid de las Juventudes Socialistas: tras plantear que "cada excursión de propaganda» de la FJS debía tener como fin «endurecer la disciplina, perfeccionar la táctica militar ... Hacer ... lo que en el ejército se denominan "maniobras", dijo que, «aunque hubo deficiencias», en el acto «hubo parte de eston. Pero de la organización de las milicias tenía buenas refetencias la DGS: así lo hace ver un informe que explica que «el jefe de la Oficina de In-

27 Elaboración propia a partir de los datos obtenidos de las declaraciones. Las Juventudes Socialistas establecían en sus estatutos que se podía pertenecer a elias hasta los treinta y cinco años, aunque a partir de los treinta era obligatorio ingresar también en el PSOE. Hay procesados que sólo participaron en el traslado o aimacenamiento de armas fy que suelen ser de más edad), que no hemos incluido para elaborar estos datos, y milicianos de los que no tenemos sus datos personales o están incompletos. Ver la composición profesional según Rosal, en RosaL, A. del, 1934. El movimiento ..., op. cit., p. 209. 
formacións dirigió una carta, el 14 de agosto de 1934, al jefe de la Brigada de Investigación Criminal, en la que le decía que «la Juventud Socialista de Madrid tiene constituídos Grupos de Acción en todas las zonas de la capitab, están elaborando «un Censo de cada zona» y utealizan simulacros de ataques». Además, M. Pastor Florit fue detenido el 25 de septiembre, y procesado por «ser jefe de escuadra de las milicias, ... divididas en ... compañías de 100 [hombres], escuadras de 10, con un jefe y un subjefes ${ }^{26}$. Por tanto, los problemas organizativos etan importantes: escaso número de hombres, pocas reuniones organizativas, conocimiento de su existencia por parte de las fuerzas del orden, ...

Un aspecto fundamental en la conformación de una organización paramilitar es su armamento, y a conseguir armas se dedicaron los socialistas en los meses anteriores a octubre. Así, los detenidos hablaron de numerosos traslados de armas. Por ejemplo, en agosto, Albar le envió a E. Rodríguez Calvo unos paquetes con armas largas que, a mediados de septiembre, Largo Caballero le pidió que entregara a Laín. Pero muchos de los ptincipales alijos de armas fueton descubiertos por las fuerzas del orden. El 14 de septiembre, en un registro previo al levantamiento de la clausura de la Casa del Pueblo establecida tras la huelga del 8, se encontraron abundantes armas; los miembros de la Junta Administrativa de la Casa del Pueblo, entre ellos, Henche, y los tesponsables de las sociedades en cuyas secretatias se habían encontrado armas, fueron detenidos el 16 de octubre; el 17, se decretó la suspensión en sus funciones de todas las asociaciones profesionales del centro. El Socialista justificó el armamento en la previsión de los trabajadores "para que no sean asaltados con toda impunidad» sus centros; Renovación planteó que el encuentro de armas en la Casa del Pueblo se produjo en "condiciones asaz sospechosas», pero también que habia mostrado «que no es broma nuestra propaganda». El 19 de septiembre, se descubrió un laboratorio de explosivos en Ciudad Lineal, en un hotel perteneciente a un ex-diputado socialista de las Cortes Constituyentes, G. Morón. En él se encontraton 90 kilos de dinamita y utensilios y líquidos para la fabricación de explosivos. Ese mismo día, fue descubierta en la Ciudad Universitaria una camioneta con armas y se detuvo a F. Ordóñez Peña, estudiante de derecho y director del

28 RosAL, A. del, 1934. El movimiento ..., op. cit., sobre las reuniones y los entrenamientos, ver p. 208, lo de Vidal, en p. 209. Las declaraciones están en AGGC, SM, 343, la de de Revuelto en f. 175; la de Escudero, en f. 9; la de Ogier en f. 289. Según Lafin, Vidal «era asesor técnico militar de Fernando de Rosa y de José Lain", lo que el teniente negó; el proceso contra él se sobreseyó (AGGC, SM, 343, la declaración de Lafin, f. 297 verso, la de Vidal en f. 422). El articulo de Renovación, está en su númeto del 14/7/34, p. 4, «Los jóvenes socialistas de la provincia de Madrid, a San Martín de la Vegan; el informe, en AHN, Fondos Tribunal Supremo, Reservados, Expediente 53, Largo Caballero, ff. 24-25, parte de un grupo de notas encontradas en el despacho de Caballero en la sede de la UGT, y que éste y García Atadell no negaton que les pertenecieran (Acta del juicio oral a Largo Caballero, AHN, Fondos Tribunal Supremo, Primera Serie, Recursos, legajo 113/443, Francisco Largo Caballero, delito de rebelión). Rosal habló de un enlace en la DGS que habria enviado estas notas (Ros/L, A. del, 1934. El movimiento..., op. cit., p. 305). Sobre Pastor, ver E/Debate, 25/9/34 y 27/9/34, p. 1 y E/ Sol, 27/9/34, p. 8. A. Orueta también dijo que Pastor era jefe de escuadra (AGGC, SM, 343, f. 248 verso).

Hixpania, L.JX/3, núm 203 (1999) 1063-1103 
departamento de propaganda de la FUE. El día 20 se encontró otro depósito de armas en Cudad Jardín, en el domicilio de un chófer socialista. Entre lo hallado, destacan paquetes de pólvora y fusiles confeccionados uen la fábrica militar de Oviedo en 1933\%. En la casa de un hombre apellidado Meneses, se encontraton 300 bombas (cuyo origen era también la fábrica de armas de Oviedo). Los registros se sucedieron durante días, abarcando sedes del PSOE, de la UGT, domicilios de militantes del partido y de la juventud, y cooperativas, y se extendieron por la provincia. Aunque los resultados fueron desiguales, además de reducir el armamento de los socialistas, dificultarian el logro de más armas y el traslado y reparto de éstas ${ }^{29}$.

Aún así, según los documentos del proceso a las milicias y testimonios como el de Rosal o Tagüeña, los socialistas todavía tenían armas en Madrid. El depósito más importante parece que estaba en la calle Alberto Aguilera, númeto 40 , que fue encontrado por la policía tras los sucesos de octubre, y en el que había, entre otras muchas cosas, un «cañón de una pesada serie $A$ fabricada en Oviedo" y «treinta y cinco cajas de cápsulas ... de la fábrica de Sevillas. La procedencia de las armas indica cierta capacidad para su obtención y traslado ilegal. En cualquier caso, el armamento disponible no parece que fuera suficiente ni siquiera para armar a los tampoco numerosos milicinnos, y casi todos los repartos de armas reconocidos se produjeron días antes de que se iniciara el movimiento (muchos milicianos, además, hablaron de repartos el mismo cuatro de octubre), aunque Turégano declaró que se le hicieron varias entregas de armas para que repartiera entre su escuadra con anterioridad, y que se le encargó que enseñara «su manejo a seis u ocho individuoss. Tampoco parece haber habido muchos entrenamientos en su uso: además de lo dicho por Turégano, sólo F. de Rosa y P. González Zubilaga dijeron haber enseñado a usar atmas a algunos individuos ${ }^{30}$.

29 AGGC, SM, 343, el relato procede de la declaración de Calvo, f. 7. Ver también declaraciones de Setién, f. 230 recto; Ogier, f. 289 recto; Mateo, f. 237 y R. Maroto Cordón, f. 236. Sobre la Casa del Pueblo, ver E/ Debate, 18/9/34, p. 2 y 20/9/34, p. 2 y El Sol, 20/9/34, p. 1; las citas, en El Socialista, $22 / 9 / 34$, p. 1 , «Unas reflexiones sobre los alijos y los complots» y Renovación, 22/9/34, p. 1, la primera en «Armas en la Casa del Pueblon; la segunda en «Preámbulo insurreccionaly; el laboratorio y los sucesos de Ciudad Universitaria, en E/ Debate, p. 1, El Sol, 20/9/34, p. 1 y 8 y E/Socialista, 20/9/34, p. 5; el alijo de Ciudad Jatdín, en El Debate, 20/9/34, p. $1 ; E /$ Socialista, 21/9/34, p. 4; el origen "asturiano» de lo encontrado, en E/Debate, 21/9/34, p. 1. El encuentro de bombas se recoge en El Debate, 30/9/34, p. 6. Para los registros, ver E/ Socialista, 22/9/34, p. 1 y E/Debate, 22/9/34, p. 1 . El hecho de que se intentasen guardar armas en la Ciudad Universitaria y el cargo que ocupaba Ordónez son una muestra del importante papel de los estudiantes en general, y de los miembros de la FUE en concreto, que ya se veía en la composición de las milicias.

31) Sobre el depósito de Alberto Aguilera ver AGGC, SM, 343, f. 116 verso y 117 recto, y las declaraciones de E. Garcia González y su esposa, C. Martínez Rivas, f. 124; López Diaz, ff. 2 y 3; y A. Martín, f 249 verso y ff. 339-340. Para otros depósitos ver, por ejemplo, declaraciones de Fesser y Setién en AGGC, SM, 343, f. 238 y de F de Rosa, en AGGC, PS M LADRD 1918, $7^{2}$. pieza, E. 10; ROSA., A. del, 1934. Elmovimiento ..., op. cit, pp. 244247 y TAGÜLNA, M., Testimonio de dos guerras, op. cit, p. 67. Sobre los repartos, ver AGGC, SM, 343, la declaración de Turégano en f. 120 recto; Ias de F. de Rosa y Zubillaga en AGGC, PS NCADRID, 1918, $7^{\mathrm{a}}$. pieza, f. 10.

Ifipunia, JJX/3, num. 203 (1999) 1063-1103 
Pero, como dice Waldmann, en la organización de acciones violentas, uningún grupo social puede hacerle, seriamente, la competencia al aparato estatal ... Lo único que pone en peligro al Estado es la posibilidad de que sus propias fuerzas de seguridad se rebelen contra el gobiernom. Resulta, por tanto, lógico que los socialistas buscaran atraerse a los militares y a las fuerzas del orden. Así, su prensa hizo hincapié en objetivos que pudieran reflejar los intereses de estos grupos, y presentó a las organizaciones socialistas como sus únicas defensoras. Por ejemplo, Renovación planteó reivindicaciones sobre los militares, destacando la política de ascensos, la situación económica, la reducción del servicio y la modificación del código militar. No había, por tanto, simplemente una «fascinación" por los militares en las Juventudes Socialistas. Según Rosal, en Madrid el movimiento contaba con simpatías en cuadros del ejército por debajo del grado de comandante. La información que tenían los milicianos era muy optimista: por poner un ejemplo, Nouvillas declaró que sus dirigentes les habían dicho que en todos los cuarteles de Madrid ... habia elementos comprometidos... con excepción del Regimiento de Caballería de Alcalás. Contamos con información sobre el teniente de infantería del regimiento númeto seis, J. del Castillo, que, según Escudero, se había comprometido a «abrir las puertas del cuarteb de dicho regimiento. Había también personas comprometidas en el Centro Electrotécnico o Parque Central de Automóviles, entre ellos el Sargento Primero V. Perruca, que era el que les facilitaría el acceso al Parque, y G. Vidal. Matilla habría hablado también con un Capitán del Regimiento de Infantería número seis, llamado Palacios, «que le comunicó la posibilidad de levantar un Batallón cuando saliera a la calle con motivo de la declaración del Estado de guerrass ${ }^{31}$.

También se contactó con guardias civiles, que facilitaron uniformes a las Juventudes Socialistas. A. del Rosal cita el grupo de las "Siete Fanegas", donde estaba el teniente socialista F. Condés, y el del cuartel de Batalla del Salado. De una entrevista con Condés surgió, según Rosal, la idea de hacer La Gaceta de la Revolución, en la que se incluyeron tcivindicaciones similares a las aparecidas en Renovación en relación con los guardias de asalto y los soldados. Según M. Nelken, su distribución se limitó "casi por completo a la capital». Estaban comprometidos guardias de asalto de los cuarteles de Pontejos y de la Guindalera. Rosal nombró, en su libro, a Colón, Matesanz, Rey, Ferrete y Moreno. De és-

31 WA.DMANN, P., «Estrategias estatales...», op. cit., p. 97. Renovación, 24/2/34, p. 1, «iCamaradas militares!»; la «fascinación» en JULIA, S., «Fracaso de una insurrección y derrota de una huelga: los hechos de Octubre en Madrid), Estudios de Historia Social, Madrid, n². 31, (octubrediciembre 1984), p. 39; sobre los contactos con militares ver ROSAL, A. del, 1934. E/ movimiento..., op. cit., pp. 215-216; AGGC, SM, 343, declaración de Nouvillas, f. 119 recto; de Escudero, f. 6; de Matilla, ff. 20-21. Aunque los implicados negaron estas acusaciones, a Pertuca, por ejemplo, la Comisión Central Pro-presos del PSOE le concedió 100 pesetas de ayuda en abril de 1935, lo que muestra que les apoyaba (ver declaraciones de Perruca y Castillo en AGGC, SM, 343, f. 23; la ayuda, en FPI AH 22-8, CE PSOE, Comités de Ayuda, Fondos, Memoria de la Comisión Central Pro-presos (abril-junio 1935), f. 22).

1hìpanit, LIX/3, núm. 203 (1999) 1063-1103 
tos, sólo hemos encontrado información sobre M. Moreno (teniente de la octava compañía de guardias de asalto (que tenía su sede en el cuartel de López de Hoyos), con el cual Rosal y F. de Rosa tuvieron varias teuniones, y sobre el guardia J. del Rey. F. de Rosa dijo que Moreno se había comprometido "a entregarles el cuartel de las Fuerzas de Asalto» y a proporcionar « 300 o 400 fusiles de los guardias». El plan era que los milicianos llevaran al cuartel a otros, como si los hubieran detenido, y se apoderaran del centro. También fue procesado M. Gañán, guardia de asalto de la misma compañía que Moreno. Algunos guardias de asalto, que declataron como testigos, hablaron de unas hojas subversivas, llamadas "Gaceta de la Revolución", aparecidas en el cuartel de López de Hoyos unos días antes de los sucesos de octubre, de las que Moreno habría dicho que le llegaban a su casa y Gañán que él las repartía. Ambos habrían expresado sus simpatías hacia una posible revolución que consideraban próxima. Pero el número de miembros de las fuerzas del orden y del ejétcito con los cuales contaban los socialistas era muy escaso. No se puede saber la atracción que estas personas ejercían en las unidades de las que formaban parte, aunque por lo que sucederá en octubre, parece que era escasa. Los socialistas no se plantearon que los militares cuando se habían movilizado había sido en apoyo de movimientos democrático-liberales, atraídos por los partidos republicanos: aunque Prieto contactase con ellos y les propusiese un movimiento de recuperación de la (tepública de abrill, no era eso lo que planteaban los socialistas en su prensa y en sus actos. Además, la declaración del estado de alarma, el 22 de septiembre, habría dificultado su actuación ${ }^{32}$.

Además, los socialistas realizaron trabajos de información, como se planteaba en el texto de Neuberg, pero parecen muy insuficientes: entre las notas encontradas en el despacho de Largo, estaban los nombres y direcciones personales de varios militares monárquicos (un teniente de Intendencia, «con cargos en el Ministerio de Guerra», un "Comandante de intendencia ... pariente del Director Genetal de Seguridad», un "comandante del Estado Mayon; ;...), un pequeño informe sobre "aparatos de radio y emisoras de la policía", y otro con los teléfonos de la DGS e indicaciones para dar informaciones falsas; en la casa de E. García González se encontraron doce planos de los distintos sectores que componían el distrito de Universidad y veintinueve del distrito de Palacio $^{33}$.

32 Ver RosıL, A. del, 1934. El movimiento..., op. cit., pp. 221-226; la idea de Nelken en NELKEN, M., , Porqué bicimos..., op. cit., p. 117,; la declaración de F. de Rosa en AGGC, PS MADRID, 1918 , f. 57. Ver en AGGC, SM, 343, declaración de Moreno, f. 218; de Rosal, f. 409 recto y en AGGC, SM, 345, ff. 1078-1085, declaraciones de los guardias de asalto J. Estevez Rodríguez, J. Alonso Sastre, J. Carvạal Cañete, N. San Román Gómez, H. Gómez Collado, D. Darío Pozo y P. Cubos.

33 Las notas se pueden ver en AHN, Fondos Tribunal Supremo, Reservados, Expediente 53, Largo Caballero, ff. 6, 29, 30, 31, 32 y 33; sobre los planos, ver AGGC, SM, 343, f. 116 verso. 


\section{OCTUBRE DE 1934 EN MADRID; ENTRE LA HUELGA PACÍFICA Y LA INSURRECCIÓN.}

La estructura de oportunidades políticas está definida, en nuestro caso, por lo que Tilly llama amenaza, que implica el grado «en que otros grupos están amenazando con hacer teclamaciones que si son exitosas, reducen las realizaciones de los intereses» del contendiente: a la política rectificadora realizada por los gobiernos radicales y la ofensiva patronal, se sumaba la concepción, por parte de las organizaciones obreras, de la entrada de la CEDA en el gobierno como ascenso del fascismo. Aunque ésto sea discutible, la sensación de amenaza era creciente, y es uno de los elementos que explica las importantes movilizaciones que hemos visto en Madrid, en un contexto en que, en el ámbito laboral, las organizaciones sindicales habían ganado importantes luchas. El cuatro de octubre, quedó constituido un nuevo gobierno con tres miembros de la CEDA. El Partido Socialista inició el movimiento tevolucionario, que tuvo distintos efectos y formas en las diferentes regiones, según la fuerza, posición política y táctica de las organizaciones participantes. El cinco de octubre, el paro era general en todas las ciudades, pero casi no se siguió en el campo, por el desgaste sufrido por los campesinos tras la huelga de junio. En Madrid, como a nivel general, los socialistas, que jugaron el papel principal, utilizaron sus propios cauces internos de comunicación para realizar el movimiento. La Junta Administrativa de la Casa del Pueblo informó que upor acuerdo de unas cuantas juntas directivas y sindicatos, se encargaron de la dirección de la huelga ... Fco. Barranco, Felipe García y Edmundo Domínguez». Según Munis, los socialistas comunicaron a la Alianza Obrera unna orden de huelga general pacífica»; M. Nelken también dijo que circularon por Madrid este tipo de consignas. Hubo participación anarquista: el PCE habló de los anarquistas que «en Asturias, Madrid y otros lugares han luchado valientemente unidos a ... comunistas y socialistas»; los sindicatos de la CNT de Madrid dijeron que "nuestra organización ha ido al pasado movimiento por solidaridad,, planteando que hubieran "pasado a primera línea si quien debía hubiera oído nuestra voz ..., dando las posibilidades que podia y debía dan?, en clara alusión a los socialistas ${ }^{34}$. Las or-

34 TuLy, C., From Mobilization..., op. cit., p. 133; Memoria de La Junta Administrativa de la Casa del Pueblo de Madrid (octubre 1934-junio 1936), Madrid, Gráfica Socialista, 1936, p. 5 (FPI, AH 23 7); Munss, G., Jalones de derrota ..., op. cit., p. 161. La Alianza Obrera de Madrid habia dirigido un comunicado a los trabajadores llamándoles a estar uen guardia» porque «las batallas decisivas van a dar comienzo" (APCE, film X (130); NLLKEN, M., żPorqué bicimos..., op. cit., pp. 152-153. Sobre la participación anarquista, ver APCE, volumen 15, Documentos Políticos PCE, 1934, "Maniffesto del PCE inmediatamente después de los combates de octubre», f. 62; la UJCE expresó la misma idea (ver APCE, film XIII (165), «Experiencias para la juventud trabajadora», $f$. 13); la cita de los anarquistas, en Revolución social, periódico de los sindicatos de la CNT de Madrid, 10/34, p. 1. También Abad de Santillán habló expresamente de la participación anarquista en Madrid (ABAD DE SANTILIANN, D., "Los anarquistas españoles y la insurrección de octubre» [1935], en El anarquismo y la revolución en España. Escritos 1930/1938, Madrid, Ayuso, 1976, p. 223).

Hi.punia, ].IX/3, núm 203 (1999) 1063-1103 
ganizaciones obreras habrían actuado, en todo caso, sin coordinarse entre ellas, aunque no se puede descartar esta coordinación en el ámbito de alguna localidad o barrio.

El viernes cinco por la mañana el paro era absoluto en Madrid capital. Ya la noche del cuatro, se había detenido a numerosas personas que repartían hojas a favor de la huelga, los establecimientos de hostelería habían cerrado, y el personal del metro, de tranvías y taxis habia abandonado el servicio, siendo sustituidos por fuerzas del Ejército, seguridad y asalto. El día cinco se publicaron El Debate, ABC, La Época, El Siglo Futuro, Informaciones y La Nación. En los demás periódicos, y en la imprenta en que se editaba la Gaceta, cesó el trabajo desde la medianoche del cuatro, pero $A$ hora salió con normalidad desde el día seis. También se declaró la huelga en diversos pueblos de la provincia, como San Lorenzo del Escorial, Aranjuez, Barajas, Colmenat Viejo, Ciempozuelos, Alcalá de Henares, Cercedilla, Chamartín de la Rosa, los dos Carabancheles o Getafe. Desde el primer momento, las autoridades se preocuparon principalmente del mantenimiento de los servicios municipales y de transporte, el abastecimiento de la población y el orden público. Durante los días de huelga, en las tahonas «se vendia pan [elaborado por personal de la Intendencia Militar y voluntarios, que también trabajaron en el mataderol a horas determinadas», aunque hubo días "en que faltaron en algunos barrios artículos de primera necesidad». La patronal madrileña apoyó totalmente al gobierno, viendo en la acción un ataque a sus intereses, así, por ejemplo, la FPM ofreció al Ministro de Gobernación los servicios técnicos y profesionales de sus asociados, así como sus automóviles y camiones ${ }^{35}$

En los servicios municipales, según E/ Sol, la huelga fue secundada, desde el primer día, "por todos" los obreros. Esto no se podía permitir, ya que afectaba a servicios esenciales para mantener una situación de relativa normalidad en la ciudad (matadero, limpieza, alumbrado,...), y porque sería la muestra más fehaciente de éxito del paro. El día seis, el Gobernador Civil de Madrid, F.J. Morata, estableció que quienes no se reintegrasen al trabajo serían "separados» de sus puestos, y se multaría o se arrestaría a quienes alterasen la regularidad de los servicios. Peto éstos «siguieron abandonados». Tampoco se podía permitir que los funcionarios estatales parasen y, por ejemplo, los carteros secundaron la huelga. El Ministerio de Comunicaciones estableció que quienes abandonasen el trabajo serían despedidos; planteamientos similares realizaron los demás organismos públicos, como el Ministerio de Hacienda, lo que indica que el número de trabajadores en huelga era importante. El 7 de octubre, el Gobierno

35 Ver $E /$ Sol, $14 / 10 / 34$, p. 4 y $A B C, 6 / 10 / 34$, p. 45 . Sobre los pueblos, ver $A B C$, $7 / 10 / 34$, p. 36. La Agrupación Socialista de Barajas informó que la huelga se había declarado el día cinco y transcurrido sin novedad, shasta el día 12 en que hicieron acto de presencia ... fuerzas de la guardia civil», que detuvieron «al Alcalde, tres concejales y a los directivos de esta agrupación», lo que parece mostrar que se dio en los pueblos una orden de huelga pacífica (FPI, AASM, 16-31 (1). Las citas se pueden ver en E/ Sol, 14/10/34, pp. 4 y 5 ; las instrucciones de la FPM, en Labor, 16/10/34, p. 6 . 
declaró suspendido el Ayuntamiento de Madrid, y destituyó a su alcalde, P. Rico (de Unión Republicana), por el «abandono de funciones y falta de asistencia al Poder público por el Ayuntamiento ... dejando desatendidos los servicios a él encomendados, contribuyendo de ese modo al desordeny. Provisionalmente, se encargó del Ayuntamiento el ministro Martínez de Velasco, y el gobernador civil designó representante suyo y responsable de los servicios municipales al coronel Pareja. El día nueve, se prohibió que se reuniese la comisión gestora de la Diputación Provincial, porque la mayoría de sus miembros lo eran por ser concejales del Ayuntamiento. La sustitución del ayuntamiento madrileño fue muy bien recibida por la prensa de derechas y por las organizaciones patronales: $A B C$ lo consideró «muy bien, aunque tardío»; Labor dijo que «Madrid ha dejado de sentir la pesadilla de ser dirigido por unos hombres incapaces, cómplices de los manejos tevolucionarios que aspiraban a destruir a Españay. Así, con el acuerdo de las fuerzas de derechas y de las patronales, la huelga fue aprovechada para acabar con el Ayuntamiento elegido democráticamente, y el gobierno controló los principales órganos de poder provinciales. Esto muestra que cun movimiento que ataca a grupos influyentes puede generar un contramovimienton y aumentar las oportunidades para la represión del gobierno y las elites ${ }^{36}$.

El mismo día siete, el coronel Pareja decretó que se consideraría que el personal municipal que no se presentara en sus puestos a unas horas fijadas, renunciaba a su cargo, y se ordenó a los propietarios de taxis que pusieran en servicio sus coches, o perderian sus licencias. Así, parte del personal municipal volvió al trabajo: según Martínez de Velasco, el nueve de octubre se habían reintegrado todos los trabajadores municipales del alcantarillado, de la Casa de Campo y de vías públicas, casi todos los conductores, el $80 \%$ de los trabajadores de los talleres generales, un $50 \%$ de los de parques y jardines y parte del personal del matadero, alumbrado y limpieza. Pero, en diversos casos, tuvieron que actuar miembros de Acción Popular, por no acudir los empleados municipales, y en algunos sitios intervino la fuerza pública, porque grupos de huelguistas intentaban impedir la vuelta al trabajo. El diez, Velasco tuvo que advertir nuevamente que se continuarian las sustituciones, lo que indica que la reintegración al trabajo no debía ser tan general. Además, el Ayuntamiento contó con la ayuda de voluntarios: la movilización de las "fuerzas del orden»" fue importante. Los miembros de las Juventudes de Acción Popular, de Renovación Española, del Partido Agrario y de los tradicionalistas prestaron servicios técnicos, condujeron transportes públicos, trabajaron en la fábrica de gas,

36 Sobre la huelga de los empleados municipales, ver $E /$ Sol, $14 / 10 / 34$, p. 5 , de donde es la cita, $A B C, 7 / 10 / 34$, p. 34, y E/ Debate, $7 / 10 / 34$, p. 3. El bando del gobernador civil está recogido en $A B C, 7 / 10 / 34$, p. 39; sobre los trabajadores estatales, ver $E / S o l, 14 / 10 / 34$, p. 4 y Rimos Oliveira, A., La revolución española de octubre, Madrid, Editorial España, 1935, p. 82. El decreto de suspensión del Ayuntamiento se puede consultar en $A B C, 9 / 10 / 34$, p. 30, de donde es su opinión, la de Labor, del 16/10/34, p. 3. La última cita es de TARrow; S., Powver in Motement, op. cit., p. 97.

Hi.punia, 1.1X/3, núm. 203 (1999) 1063-1103 
en el servicio de limpieza, en el transporte de alimentos, fabricación de pan, aprovisionamiento a colegios y venta de periódicos. Pero la mayoría de los servicios municipales se realizaron, cuando se hicieron, protegidos por fuerzas del Ejército o guardias de asalto. La Falange ofreció su ayuda al gobierno para hacer frente a los revolucionarios y para suplir a los obreros en huelga con miembros de sus sindicatos; el día siete, realizó una manifestación de apoyo al Gobierno. $A B C$ defendió claramente la necesidad de una umovilización ciudadanay: «todos los ciudadanos, por todos los medios y con todo lo que puedan hacet, contra la huelga revolucionarias. También El Debate pidió que la población hiciera frente activamente a la huelga: «que ... adviertan que se atenta contra las libertades públicas y que las defiendan». El Círculo Mercantil de Madrid y la Unión Económica mandaron escritos de adhesión al Gobierno ${ }^{37}$.

$\mathrm{Al}$ ser declarada la huelga ilegal, numerosas asociaciones patronales y empresas anunciaron que consideraban rescindidos los contratos de aquellos trabajadores que participaban en ella, aprovechando la huelga para sustituir a sus empleados por personal no afiliado a sindicatos de clase: las empresas del Metro y Tranvías, de la industria panadera, del gas y de electricidad, «da Asociación de hoteles, sanatorios y otras varias empresas", la FPM, la Unión Patronal de las Artes del Libro, la Agrupación Patronal de la Madera, y la Unión Patronal de Servicios. Todas advertían a sus miembros que los salarios y bases de trabajo vigentes debían ser respetados. Los trabajadores que habían hecho la huelga debían solicitar el reingreso, con nuevos contratos. El nueve de octubre, según El Debate, no hubo "ni un comercio cerrado", lo cual no es extraño, ya que la DGS envió una circular a las comisarías de Madrid en la que se ordenaba que fuesen detenidos todos los dueños de las tiendas que no abriesen y se les impusiese una multa de 20.000 pesetas. Pero el ministro Jiménez Fernández tuvo que advertir que uel Gobierno ... no está dispuesto a consentir los abusos iniciados por algunos mal llamados comerciantes al intentar aumentar los precios de ciertos artículos de primera necesidady. Los huelguistas también actuaron, y «en algunos establecimientos de comestibles se recibieron ... avisos telefónicos diciendo que por orden de las comisarías de los respectivos distritos se procediera a echat los cierres inmediatamentes ${ }^{38}$.

El once de octubre la normalidad era más acentuada: se intensificaron los servicios de transporte con personal nuevo, y se regularizaron el servicio de

37 El decreto está recogido en $A B C, 9 / 10 / 34$, p. 32; la información de Martinez de Velasco, en $A B C, 11 / 10 / 34$, p. 22 ; las reacciones de las organizaciones politicas, en $A B C$, $10 / 10 / 34$, p. 4 , y El Debate, $9 / 10 / 34$, p. 7 . Ver también E/Sol, $14 / 10 / 34$, p. 5 . El ofrecimiento de la Falange está publicado en $A B C, 7 / 10 / 34$, p. 56; la manifestación, en $A B C, 9 / 10 / 34$, p. 45; las otras adhesiones, en E/ Debate, 9/10/34, p. 3. Las citas son de $A B C, 5 / 10 / 34$, p. 27, «Enérgicas medidas de prevención ante los intentos revolucionarios», y E/ Debate, 5/10/34, p. 1 , «Serán derrotados».

38 Las instrucciones de empresas y asociaciones se recogen en $A B C, 9 / 10 / 34$, p. 32 , $10 / 10 / 34$, p. 31 y $12 / 10 / 34$, p. 29. La cita de El Debate es del 10/10/34, p. 2; la información sobre la circular de la DGS está tomada de $A B C, 9 / 10 / 34$, p. 35 ; las palabras de Jiménez Fernández, de $A B C, 10 / 10 / 34$, p. 26; la última cita es de $E /$ Sol, 14/10/34, p. 5. 
limpieza y el de pan y artículos de primera necesidad; persistía la huelga con fuerza en algunos ramos, como Artes Gráficas, Camareros o Construcción, a pesar de las constantes amenazas de despido. El día doce, se reintegraron al trabajo los empleados de transportes, los camareros y parte de los panaderos. También se iba normalizando la situación en los distintos pueblos de la provincia: por ejemplo, en Chamartín de la Rosa se acordó, el once de octubre, reanudar el trabajo en todos los servicios municipales. El trece, Martínez de Velasco informó que «había decretado la suspensión en sus cargos de todos los funcionarios que han secundado la huelga y no se han reintegrado al trabajo en el plazo marcado", ordenando, respecto a los que lo habían hecho, que «se les instruya expediente para las responsabilidades a que pudiera haber lugan. Esto supondría el despido de muchos trabajadores. Ese mismo día quedaron totalmente normalizados los servicios municipales, y el ministro de Gobernación consideró terminada la huelga en Madrid, aunque hasta el lunes quince no entraton al trabajo todos los oficios. Con los dirigentes detenidos y los contactos entre las organizaciones rotos, la orden de vuelta al trabajo no se dio en buenas condiciones: el doce de octubre se autorizó a la CNT a repartit hojas en las que se aconsejaba la vuelta al trabajo; Munis dijo que el día 13 los socialistas dieron dicha orden; según la Junta Administrativa de la Casa del Pueblo, la huelga terminó upor acuerdo que se concertó en el Gobierno Civil con los representantes de Metalúrgicos, Madera, Artes Gráficas, Transportes, Gas y Electricidad y Edificación', los sectores más organizados de la UGT de Madrid ${ }^{30}$.

La huelga general no bastaba para el objetivo buscado (fuera éste la radicalización de la República o una República socialista): la insurrección armada no se subordinaba a la huelga general, ni se creía, como plantea S. Juliá, que la uexpectativa y preparación» generada por ésta sirviera para «derrocar al gobierno». Por esto, a la vez que se inició la huelga, empezaron los actos insurreccionales. Pero la acción de las distintas secciones de las milicias no tuvo la misma intensidad y en todos los sectores fue perdiendo fuerza paulatinamente. Se pueden distinguir dos momentos: la oportunidad que se abrió a las milicias con la entrada en el gobierno de la CEDA, que produjo los intentos insurreccionales más serios entre la madrugada del cuatro de octubre y el seis del mismo mes, y la desmovilización, que se inició al fracasar los intentos de ocupación de los centros públicos y los contactos con las fuerzas del orden. Los principales protagonistas de las acciones insurreccionales fueton jóvenes. Las autoridades, en previsión de acciones violentas, dispusieron equipos militares para que se hicieran cargo de los servicios de protección y vigilancia en las estaciones de metro, tranvías y autobuses, en los registros del agua, y en fábricas de gas y electricidad, en el Palacio de Comunicaciones, la sede de la Telefónica y en los distintos

39) La primera cita es de E/Sol, 14/10/34, p. 5; la segunda y la autorización a la CNT, en E/Sol $14 / 10 / 34$, p. 1 , «Consejo de Ministros»; el informe de la Casa del Pueblo en Memoria de la Junta Administrativa..., op. cit., p. 5; MLinis, G., Jalones de derrota.., op. cit., p. 166.

Hi.pantia, LJX/3, núm. 203 (1999) 1063-1103 
ministerios y edificios públicos. Los centros socialistas, comunistas y anarquistas fueron clausutados ${ }^{40}$.

Los grupos de las milicias de los que disponemos de información se teunieron en la noche del día cuatro para actuar. Nouvillas declaró que se querín asaltar todos los cuarteles, con la complicidad de miembros de los mismos, «siendo los que contaban como más seguro los regimientos número seis [cuartel de Moret] y treinta y unos (en el primero estaba destinado Palacios y en el segundo Moreno). Laín reunió a los distintos jefes de sección y de escuadra del primer sector, a las diez y media de la noche, en un bar junto a la plaza de la Moncloa. El plan era que al abrir la puerta del cuartel de Moret «los elementos comprometidos», "entraría la primera compañia, ... [y] dominaría el cuartel». Muchos miembros de las milicias fueron detenidos mientras se preparaban para actuar o esperaban la participación de los militates: por ejemplo, la cuarta compañía de asalto informó que en las calles Blasco Ibáñez, Romero Robledo y en el Paseo de Rosales se produjeron enfrentamientos con grupos de personas armadas; la quinta sostuvo un encuentro, en torno al cuartel de Moret y la calle Ferraz, con grupos que (invitaban a los soldados a sublevarse»; mientras que la décima compañía de servicios locales disolvió diversos grupos en las calles Santa Cruz de Marcenado, Mártires de Alcalá, Ronda del Conde Duque y Blasco Ibáñez. Aunque las puettas del cuartel no se abrieron, se emplazó una ametralladora y se intentó asaltarlo. También se produjo un ataque al Parque Central de Automóviles, y los ataques a éste se sucedieron hasta el día siete: el teniente coronel J. Lahuerta, jefe de dicho centro, declaró que «a las siete de la tarde del día cinco fue tiroteado el Cuartel contestando la fuerza y a partir de esta hora y hasta la madrugada del siete continuó el fuego a intervalos;; en la madrugada del seis, el sargento Perruca había intentado abrir una puerta del cuartel, y otros militares se lo impidieron y lo arrestaron ${ }^{41}$.

En el segundo sector, todas las compañias tecibieron la orden de encontratse en las cercanías del Círculo Socialista de Prosperidad. El enfrentamiento en éste, en la noche del cuatro al cinco, fue uno de los principales de las jornadas

40 Las citas son de JuLIÁ, S., «Firacaso de una insurrección ...», op. cit., pp. 40-41. Araquistain ya dijo que da mayoría de los lideres adultos o se apartaron del movimiento o fueron a remolque de los jóvenes" (ARAQuisTAIN, L., "La revolución española de Octubre», en VV.A., La revolución española de Octubre, Santiago, Editorial Occidente, 1935, pp. 19-20). Las medidas de protección se recogen en $A B C, 5 / 10 / 34$, p. 27.

41 Sobre el ataque al cuartel de Moret, ver AGGC, SM, 343, declaración de Escudero, ff. 5 y 6; de Revuelto, f. 176 verso; de Nouvillas, ff. 118-119; Muñoz, ff. 74 y 75; Turégano, f. 121, y Puig Guardiola, f. 84, y AGGC, SM, 345, «Relación de los encuentros que ha tenido la fuerza pública con los revolucionarios», la información de la décima compañia de servicios locales en f. 1135; de la cuarta compañía de asalto, $f .1140$; de la quinta, f. 1141. Las citas son de la declaración de Nouvillas. Con relación al centro electrotécnico, ver AGGC, SM, 343, declaración de Nouvillas, ff. 118-119; de López Diaz, f. 13 recto; Pascual García, f. 193 verso y 194 recto, y García Asenjo, f. 194 verso, y el atestado policial, f. 193 recto; la declaración del teniente coronel, en f. 429. Para ambos casos, ver también $A B C, 5 / 10 / 34$, p. 28, E/ Sol, 14/10/34, p. 4, y RAmos Ol.iverRA, A., La renolución..., op. cit., pp. 80-81.

f.i.punia, LIX/3, núm. 203 (1909) 1063-1103 
de octubre en Madrid. Entre los revolucionarios, se encontraron siete heridos (uno murió poco después); se detuvo dentro de la casa a unas 80 personas y, en los alrededores, a otras 120 , y se encontró numeroso armamento. También en este sector se contactó con fuerzas del orden. Según Moreno, de Rosa le visitó a la una de la mañana del cinco y él le dijo que le avisaran para actuar, pero no le volvió a ver. F. de Rosa declaró que el Teniente les traicionó, por lo que «desistieron de sus propósitos». El teniente coronel Muñoz Grande, jefe de los guardias de asalto, explicó que Moreno prestó cuantos servicios se le encomendaton, pero que "para el reparto de armas y concentración de rebeldes en la Prosperidad ordenó fuera sólo un pelotón', lo que era, según él, claramente insuficiente, y consideraba que las bajas que había habido entre los guardias (un muerto y tres heridos), eran responsabilidad del teniente. El guardia Cubos Collado hizo una declaración similat. Los otros guardias implicados tampoco pudieron hacer mucho: el día cinco, Gañán no se presentó a trabajar; mientras que del Rey fue con ropa distinta a la que llevaban el resto de los guardias, lo mismo que hizo Gañán cuando se reintegró al servicio al día siguiente (lo que sus compañeros interpretaton como una señal para distinguirse de los demás, convenida con los revolucionarios). P. Cubos Collado dijo que no sólo Gañán se había dado de baja, sino que exgualmente otros guardias, los cuales cuando vieron que se había resuelto todo favotablemente a las fuerzas del gobierno se dieron de altas. También se frustró el asalto al Parque Móvil de la Guardia Civil que, según de Rosa, había proyectado con el teniente Condés, y para el cual usarian uniformes de dicho cuerpo. Este proyecto fue confirmado por $\mathrm{F}$. Redondo Brea. A pesar de ésto, el día cinco hubo nutridos tiroteos en Cuatro Caminos, Tetuán y las Ventas, $\mathrm{y}$ uen todo el distrito de Chamberí ... se dieron tepetidas cargas disolviendo grupos" ${ }^{42}$.

Las acciones del tercer y cuarto sector fueron menores. Según Benavides, en el tercero, ulas milicias se limitaron a concentrarse y a esperat que los elementos amigos del cuartel de María Cristina, del cuartel de cartos de combate y del de la guardia civil de la Batalla del Saladon actuaran y, como no lo hicieron, «el jefe de sector ordenó la retirada». Los informes de las fuerzas del orden sobre el cuatro de octubre sólo recogen fuertes tiroteos en Atocha. El día cinco, su actuación aumentó, y hubo intensos tiroteos en diferentes zonas de estos

42 Sobre el enfrentamiento en Prosperidad, ver AGGC, SM, 345, "Relación de los encuentros ...), f. 1138 y 1143; AGGC, SM, 343, declaración de Balboa, f. 310 recto; de Molina Clemente, f. 307 recto; de Carmona, f. 232 verso; de los hermanos Maroto, f. 236 verso y 237 recto; de Merín, f. 237 verso, y de Fesser, f. 238 recto; $A B C, 5 / 10 / 34$, p. 28 y p. 35 . La declaración de Moreno, en AGGC, SM, 343, f. 218 verso. Según él, habia hablado con los revolucionarios para descubrir su plan, y no informó a sus superiores "porque se le pasó este detalle» (sic). La declaración de F. de Rosa está en AGGC, PS MADRID 1918, $7^{\mathrm{a}}$ pieza, p. 7, la de Brea, en AGGC, PS MLADRID 1918, f. 119; la de Cubos, en AGGC, SM, 345, f. 1085 verso; la de Muñoz Grande, en AGGC, SM, 343, f. 417. También Benavides habló de la traición del teniente Moreno (BIENAvides, M., La revolución fue asi (octubre rojo y negro), Barcelona, Imprenta Industrial, 1935, p. 71). Para las acciones del día cinco, ver AGGC, SM, 345, ff. 1141-1142. La cita es de este último folio.

Hi.paniu, JIX/3, núm. 2013 (1999) 1063-1103 
sectores (alrededores de la Glorieta de Atocha, Palacio de Comunicaciones, ...), en los que participaron varias compañías de la guardia de asalto, la primera "coadyubando [sic] con fuerza del Ejército». El seis de octubre se tirotearon los cuarteles de Puerta de Toledo y Pontejos, y el siete, el cuartel de la Guardia Civil de la calle Batalla del Salado. Pero la mayoria de las acciones tienden a mantener la huelga, más que a realizar ataques ofensivos: así, en la Puerta del Sol, calles Arenal y Mayor, Ronda de Valencia, Paseo de las Delicias, ... se disolvieron grupos que impedían la venta de periódicos o el tráfico de vehículos. El primer y el segundo sector de las milicias prosiguieron su actuación. El día seis hubo un ataque coordinado a las comisarias del Congreso, Palacio, Inclusa y Buenavista, otro a la central Telefónica de la calle Hermosilla, y otro contra la DGS. También se intentó asaltar el Ministerio de Gobernación, y se volvió a atacar el cuartel de la Montaña. La Puerta del Sol quedó desierta y «los pocos transeúntes que circulaban lo hacían llevando los brazos en altom. Se produjeron fuertes tiroteos entre grupos armados y guardias civiles y de asalto en Tetúan y Cuatro Caminos, y se atacó un cuartel de la Guardia Civil en Guzmán el Bueno. Según la novena compañía de asalto, en los «distritos de Buenavista y Congreso ... la fuerza fue agredida a tros, no respondiendo... por temor de herir a las fuerzas del Ejército que se confundian con los revolucionarios». Por la noche, hubo tiroteos en «todo Madrid» y se intentaron asaltar dos puestos de la Guardia Civil (uno en el Puente de Segovia y otro en el barrio de Terol). Un testigo de los sucesos dijo que el seis elos pocos tranvías, autobuses y taxis manejados por soldados» tuvieron que «retirarse en vista de las agresiones»; «los días 7 y $8 \mathrm{Ma}-$ drid parecía una ciudad muerta. Solamente los tiroteos ponían una nota de ruido en las calles». Se produjeron ataques a personalidades políticas importantes, lo que muestran cietta preparación informativa: se tirotearon los coches de Jiménez Fernández y de un coronel del regimiento de Saboya, el día seis; y se atacaron, el siete de octubre, los domicilios del ministro de Obras Públicas y de Lerroux ${ }^{43}$.

Los miembros de las fuerzas del orden comprometidos no actuaron prácticamente. Es difícil que una actuación eficaz del escaso número de oficiales comprometidos hubiese permitido el éxito, pero los milicianos tealizaron un último intento para lograr su participación: según Escudero, el siete de octubre, Matilla se reunió con dos militares (uno, al parecer, era el Capitán de Infantería E. Díaz Tendero), y fue a ver al teniente Castillo; S. Fernández González decla-

43 Sobre las acciones del tercer sector, ver BiNAvidis, M., La revolución fue asi..., op. cit., pp. 75-76. Los informes de las fuerzas del orden están en AGGC, SM, 345, ff. 1138, 1139 y 1143, la cita es de f. 1138. Las acciones del seis y del siete, en AGGC, SM, 345, f. 1139. Para el primer y segundo sector, ver $A B C, 7 / 10 / 34$, p. 34-36 y 39; E/So/, 14/10/34, p. 4, y los informes de la $1^{\mathrm{a}}$., $2^{\mathrm{a}}$. y $6^{\mathrm{a}}$. compañía de servicios locales (AGGC, SM, 345, ff. $1132-1134$ ). La primera cita es de AGGC, SM, 345, f. 1143, la segunda, de E/ Sol, el testimanio, de Matilio, L.O., El octubre español, México D.F., Talleres Gráficos de la Nación, 1935,95 pp., la primera cita en p. 33, la siguiente, en p. 78. Los ataques a personalidades están recogidos en AGGC, SM, 345, f. 1132.

Hiponia, LIX/3, núm 203 (1999) 1063-1103 
ró que «dos individuos que le enseñaron el emblema de las Juventudes Socialistas, quisieron darle unas hojas", para que las repartiese en el cuartel. También se mantuvo cierta coordinación: E. Puente estuvo, desde el inicio del movimiento y durante cuatro o cinco días, en la casa de M.L. Hidalgo Rivas, donde tenía un "cuartel, recibía instrucciones y daba órdenes»; F. de Rosa se reunió con Laín varias veces; $\mathrm{S}$. Calvo declaró que hasta el viernes doce de octubre, se reunía todos los dias con Laín uen el paseo de Alberto Aguilera, sobre las once horas, acudiendo ... todos los jefes de escuadra, ... y los muchachos que servian de agentes de enlace entre ellos». Pero, aparte de la propia dirección de los jefes de sector y de Puente, no hubo ninguna otra ${ }^{44}$.

Por lo que respecta a la provincia, hay pocos actos insurreccionales destacados, lo que refuerza la idea de que se dio una orden de huelga pacífica. En Villaverde, se intentó asaltat un tren de mercancías; en Carabanchel hubo un tiroteo, en el que se detuvo a numerosos miembros de la Juventud Socialista, y se intentó asaltar la Escuela Central Automovilística; se cercó el cuartel de la Guardia Civil de Colmenar Viejo, donde también se cortaron las líneas telegráficas y telefónicas y se causaron desperfectos en el canal de Santillana, por lo que hubo que enviar fuerzas desde Madrid ${ }^{45}$.

Fracasados los asaltos a los centros públicos, realizados casi siempre por grupos no muy numerosos, lo que muestra las limitaciones de las milicias, y los llamamientos a los cuarteles, se inició la desmovilización: a partir del día siete, las acciones insurreccionales se redujeron a «paqueos» (tiroteos desde azoteas, terrazas o tejados), sabotajes, lanzamientos de bombas contra medios de transporte, intentos de impedir la venta de periódicos, asaltos a tiendas y ataques aislados a guardias civiles, guardias de asalto, ..., sin coordinación ni objetivos definidos e importantes, que buscaban principalmente evitar la vuelta al trabajo y el restablecimiento de la normalidad. Pero estas acciones no eran contrarias a la posición de algunos dirigentes socialistas, según los cuales «era preciso a todo trance continuar la huelga para poder conseguir sus fines revolucionarios». Rosal explicó que "después de una entrevista con Caballero, se les daba la orientación a sus jefes [de las milicias] de que mantuvieran una acción sistemática de hostigación, de escaramuzas, a través de toda la ciudady. El siete de octubre, hubo «tiroteos en muchos lugares de Madrid), destacando el cerco de la comisatía de Buenavista. Ese día se declaró el estado de guerra. El bando dictado por el general de primera división V. Cabanellas en aplicación de éste, se leyó, como se hacía normalmente, de una forma que buscaba con la esceni-

44 AGGC, SM, 343, declaraciones de Escudero, f. 6 recto y f. 15; la de Fernández, obrero del Centro Electrotécnico, en f. 499 verso; la de Matilla, en f. 20; el «cuartel» de Puente, de la declaración de A. Martín, f. 250 recto; la declaración de Calvo, en f. 180; la de F. de Rosa, en AGGC, PS MADRID, 1918, $7^{2}$. pieza, f. 10.

${ }_{45}$ Los sucesos de Carabanchel están recogidos en $\mathrm{E} / \mathrm{Sol}, 14 / 10 / 34, \mathrm{p}$. 4; los de Colmenar, en $A B C, 7 / 10 / 34, \mathrm{p} .37$. La agrupación socialista de este último pueblo dijo tener ados compañeros presos en el penal de Chinchilla y una viuda con cinco hijos de una víctima de los sucesos de octubre" (FPI, AASM, 16-37, 2).

Hiqutniu, J,IX/3, núm. 203 (1999) 1063-1103 
ficación desanimar a los insurrectos: la lectura la realizaron, en la Puerta del Sol, dos secciones del Regimiento de Infantería 31. Además, el comandante militar de Madrid ordenó que los porteros o guardas de los edificios, terrazas u obras comprobasen la identidad de los que entrasen en los edificios, de lo contrario, serían considerados cómplices de los tiroteos que se produjeran; «la misma disposición se aplicaría a los serenos en sus horas de servicio nocturnon ${ }^{46}$.

El lunes ocho «durante todo el día los tiroteos ... se produjeron con insistenciay, tanto en el centro, como en los barrios periféricos y pueblos cercanos, como Chamartín de la Rosa. Se atacaron varias comisarias (entre ellas, las de Congreso, Universidad y Puente de Vallecas), el depósito de máquinas de la estación MZA, la central eléctrica de Pacífico, el Canal de Lozoya, el cuartel de María Cristina, la estación de tranvías de Cuatro Caminos y el garaje del Parque Móvil de la DGS. La segunda compañía de servicios locales sostuvo tiroteos junto a los domicilios del Secretario de Gobernación y de Salazar Alonso. A partir del nueve de octubre, las acciones fueron menores, produciéndose tiroteos por individuos aislados en pocos puntos de Madrid, principalmente en las barriadas obreras, que continuaron, con cada vez menos intensidad, hasta el catorce. Pero las autoridades no se sentían seguras, ya que el día nueve «sobre Madrid volaton ... algunos aeroplanos militares» para «inspeccionat las azoteas», y, por la noche, uen diversos sitios estratégicos se colocaton reflectores para iluminar los tejados y azoteas». Siguió habiendo acciones milicianas aisladas en la zona del segundo sector: la primera compañía de asalto destacó un encuentro con "(revoltosos» que agredían al ejército e intentaban apoderarse del cuartel de la guardia civil de Las Ventas. Comenzaron a ser detenidos los dirigentes de las organizaciones obreras: el ocho se detuvo, entre otros, a C. Hernández Zancajo y S. Carrillo, a los dirigentes de la UJCE Medrano y Rozado, y a siete miembros de la CNT; el nueve se detuvo, en Salamanca, a M. Albar; el diez, al presidente del sindicato metalúrgico ugetista «El Baluarte», ... Se realizaron numerosos tegistros, se encontraron bastantes armas y fueron detenidos diversos milicianos. El doce de octubre, los miembros de las milicias recibieron la orden de volver al trabajo: según S. Calvo, «Laín les dijo que quedaba disuelta su escuadra y que fueran a presentar las instancias para reintegrarse al trabajom. El trece, se encontraron armas y municiones en una casa del barrio de Tetuán y, por las declaraciones de los detenidos, se descubrió el depósito de armas de Alberto Aguilera

46 La primera cita es de la declaración de L. Villarba, AGGC, 343, f. 175 recto; RosA., A. del, 1934. El movimiento..., op. cit., pp. 261-262. También Benavides escribió que se dio esta orden (BENAVIDEs, M., La revolución fue asi... op. cit., p. 79). Sobre las acciones, ver $A G G C$, SM, 345, ff. 1134-1135 y 1142. La cita es de E/Sol, 14/10/34, p. 4. El bando se puede ver en E/ Debate, $7 / 10 / 34$, p. 4. Ya por la tarde ael Regimiento de Caballeria número tres, de guarnición en Alcalá de Henares, con todos sus elementos de combate ... recorrió las principales vias madrileñas». Este regimiento estaba en Madrid desde el día seis y, según la novena compañía de asalto, al entrat en la ciudad, se produjo un tiroteo contra él "desde los barrancos del Puente de Ventas" (ver la primera cita en $A B C, 9 / 10 / 34$, p. 33; la segunda, en $A G G C$, SN, 345, f. 1143). Sobre los porteros y serenos, ver $A B C, 9 / 10 / 34$, p. 33 .

Ihitunia, IJX/3, núm 203 (1999) 1063-1103 
y otro en la calle Tutor. En total, según los periódicos, en Madrid había ya unos dos mil detenidos por participar en el movimiento. Las estadísticas oficiales hablaban de 14 muertos desde el cinco al ocho de octubre; Ramos Oliveira dijo que al trece de octubre, las autoridades elevaban esta cifra a 16, y hablaban de 40 o 50 heridos. Las detenciones de participantes en el movimiento revolucionario, encuentros de armas,... se sucedieron durante el resto del mes. El día 19, fue detenido J. Díaz Otero, en cuya casa se encontraron 18 uniformes de la guardia civil; por su declaración se encontraron otros 26 , y dos uniformes completos de oficial del mismo cuerpo, en el domicilio de A. Ares Menéndez. Fueron procesados el treinta de octubre por rebelión militar todos los miembros de la escuadra de Ares y otras 6 personas, entre ellos, el teniente Condés y otros dos guardias civiles ${ }^{47}$.

La labor de la prensa y otras publicaciones. Al igual que con relación a la huelga, la prensa jugó un papel muy activo en el establecimiento de posiciones y percepciones ante y sobre la insurrección: la prensa de derecha y de extrema derecha realizó un duro ataque contra los socialistas, pidiendo su ilegalización. Las críticas principales se centraron en sus dirigentes, lo que se usaría, también, como recurso propagandístico, para hacer desistir a los milicianos de actuar: por ejemplo, El Debate planteó que «los jefes se han perdido, ... han sido algunos obreros engañados los que han ofrecido el pechoi); $A B C$ advirtió de la propagación de mentiras sobre que «el triunfo del gobierno actual traerá como consecuencia la inmediata rebaja de todos los jornales», y "que empiezan a escasear los víveres en Madrid). Al generalizarse los paqueos, les restó importancia: las armas utilizadas "tienen un rendimiento muy limitado", y los tiradores «en general son gentes que han recibido dinero para hacer la revolución y tienen que justificarlo de alguna manera disparando al airen (otra forma de deslegitimar a los revolucionarios) ${ }^{48}$.

Durante los días de huelga circularon muchas octavillas y un número importante de individuos fue detenido por repartirlas. Las organizaciones madrileñas del PCE editaron numerosas octavillas e, incluso, un boletín de huelga diario, que pretendían informar de las acciones realizadas en Madrid, de la situación en el resto de España y planteat propuestas de acciones. Aunque al principio era bastante veraz, los últimos días mantuvo una visión favorable a la insurrección alejada de la realidad, seguramente con el objetivo de animar a la

47 Las acciones del día ocho se pueden ver en AGGC, SM, 345, f. 1132. La primera cita es de $E /$ Sol, $14 / 10 / 34$, p. 4 . Sobre el nueve, ver $A B C, 10 / 10 / 34$, p. 46, los aviones en p. 37 ; los reflectores en p. 27 (recogido también en $E / S o /, 14 / 10 / 34$, p. 4). El informe de la primera compañía está en $A G G C$, SM 345, f. 1138. Para las detenciones, ver $A B C, 9 / 10 / 34$, pp. 35 y 47, y 11/10/34, p. 22, y El Debate, 10/10/34, p. 8; la declaración de Calvo, en $A G G C, S M, 343$, f. 180. El número de detenidos se recoge en $A B C, 11 / 10 / 34$, p. 46 ; el de muertos, en $A B C$, $9 / 10 / 34$, p. 34 y Ramos O..IvialR, A., La revolución..., op. cit., p. 89 . Sobre los uniformes, ver las detenciones en $E / D$ ebate, $20 / 10 / 34$, p. 2, y $A B C, 20 / 10 / 34$, p. 41; las declaraciones, en $A G G C$, PS MADRID, 1918, $7^{2}$ pieza, f. 8; los procesados, en AGGC, SM, 343, ff. 445 y 446.

48 E/ Debate, $9 / 10 / 34$, p. 1, "Para consolidar el triunfo"; $A B C, 9 / 10 / 34$, sobre el trabajo, p. 21 , los alimentos en p. 35 y los paqueos en p. 50.

Inipataid, JIX/3, núm. 203 (199)) 1063-1103 
acción. Refleja las dificultades para la realización de acciones insurreccionales (pasó de pedir acciones de masas en el primer boletín, a hablar de asaltos de tiendas y quema de conventos en los últimos) y de mantenimiento de los canales de información (en los últimos días dejó de incluir noticias sobre los sucesos en provincias, no informando ni sobre Asturias). La labor propagandística de las organizaciones socialistas parece que fue menor, y no hemos encontrado octavillas realizadas por ellos. Las Juventudes Comunistas y Socialistas de Madrid editaron una conjuntamente, dirigida a los «jovenes trabajadores», que muestra un desbordamiento de las segundas por las primeras, porque utilizaba un lenguaje que no era el de las Juventudes Socialistas, sino que refleja los elementos que ésta había rechazado en las reuniones con la UJCE: decía que «los Soviets están constituídos" y pedía la creación de kalianzas obreras y campesinas». Contamos con otra octavilla, más cercana a la política de las organizaciones socialistas, que recuerda las convocatorias de la huelga de septiembre, ya que, dirigida también a los «jóvenes trabajadores de Madrid», está firmada «por las organizaciones madrileñas, el comité ejecutivo». Pedía "tadicalizar la huelga» e impedir que se restablecieran los servicios (consignas que se dieron a los milicianos socialistas) ${ }^{49}$.

\section{LAS CONSECUENCIAS DEL OCTUBRE MADRIIEÑO}

El resultado de la insurrección de octubre de 1934 cambió la estructura de oportunidades políticas de todos los participantes en la conflictividad social y política madrileña. Favoreció las oportunidades de acción colectiva de las organizaciones patronales, que expresaron su satisfacción por el triunfo del gobierno. La FPM dijo que "por fin nos sentimos gobernados con acierto». Al amparo de la represión, detenciones y clausuras, los patronos procedieron a una depuración de plantillas y empeoraron las condiciones de contratación, lo que llevó al Ministerio de Trabajo a publicar, el 18 de octubre, un decteto que disponía que se debían mantener las disposiciones vigentes sobre condiciones de trabajo y salatios. En diciembre, el ministerio restableció la jornada de 48 horas en las industrias siderometalúrgicas, lo que, para la FPM, significaba «la reparación de una injusticias ${ }^{50}$.

El fracaso de la insurrección supuso, también, la recuperación del poder político por las fuerzas conservadoras en los órganos locales y provinciales de Madrid. El 17 de octubre, el gobierno declaró disuelta la Comisión Gestora de

49) Las distintas octavillas se pueden ver en APCE, film VIII (114), IX(127), IX (120)); los boletines diarios en APCE, film VIII (115); las dos octavillas comentadas, en APCE, film X (130 y 125, respectivamente). Además, el siete de octubre, en el Palacio de Comunicaciones, fueron arrestados cuatro oficiales que estaban usando los telégrafos para transmitir cnoticias falsas" a las provincias (E/Sol, $14 / 10 / 34$, p. 4 ).

50 Labor, $16 / 10 / 34$, p. 1 la opinión; el restablecimiento de la semana de 48 horas en su número del $8 / 12 / 34$, p. 15 . La jornada de 40 horas semanales se habj́a establecido tras la huelga general de metalúrgicos.

Hitpartiu, LIX/3, núm. 203 (1999) 1063-1103 
la Diputación Provincial y nombró nuevos miembros, casi todos militantes de la CEDA y del Partido Radical. Salazar Alonso fue nombrado nuevo delegado del gobierno en el Ayuntamiento de Madrid, el día 19. El 27, se convirtió la suspensión del Ayuntamiento en destitución, lo que fue recibido por Labor con un «ya era hora». Se constituyó la Comisión Gestora que sustituiría a los concejales suspendidos, formada por 20 miembros. La lista de éstos fue aprobada previamente por el Gobierno. Para conformarla, además, Salazar Alonso se había entrevistado con Gil Robles, para que desistiera del propósito inicial de la CEDA de tener puestos en proporción al número de votos y de diputados. Encontramos en la gestora a las «fuerzas vivas» de Madrid: el vicepresidente de la Cámara de Industria, el del Círculo de la Unión Mercantil, un vocal de la Cámara de Comercio, el secretario de la FPM, además de miembros de la CEDA, del Partido Agrario, del Liberal Demócrata y del Radical. El 30 de octubre se eligió a Salazar Alonso presidente de la comisión. También se destituyeron los ayuntamientos de Carabanchel Alto y Bajo, Chamartín de la Rosa, ... hasta llegar a un número de 38 ayuntamientos suspendidos en la provincia, justificándolo en su falta de auxilio a las autoridades durante los días de la insurrección. Todo esto muestra un deseo claro de acabar con las instituciones contrarias al nuevo gobierno central, además de controlar una ciudad tan importante como la capital de la República ${ }^{51}$.

Desde la patronal y la prensa de derecha se favoreció el fortalecimiento de los sindicatos no marxistas. El Debate defendió la unión de estas organizaciones, haciendo un llamamiento directo a las madrileñas. El nueve de octubre, se formó un comité de enlace de éstas, que se erigió en comisión organizadora de un nuevo movimiento sindical, el Frente Nacional del Trabajo. Entre sus miembros se encontraban los Sindicatos Obreros Católicos, la Unión Obrera de Oficios y Profesiones Varias y el Sindicato Profesional de Obreros del Transporte y similares, de Madrid. Pero al nombrar a nuevos adheridos a dicho Frente, sólo pudieron citar, de la provincia de Madrid, a la Sociedad de Oficios Varios de Alcobendas. La Falange, por su parte, buscó ampliar su influencia sindical: el 10 de octubre, publicó una nota de su grupo metalúrgico convocando a los desempleados en su sede «para darles trabajo»; una nota similar publicaron sus «Sindicatos Gráficos». Claro que había motivos para hacerlo, ya que, según Democracia, habian sido despedidos unos 8.000 trabajadores ( 900 del ayuntamiento, 550 del servicio de tranvías, 350 de empresas ferroviarias, 150 del metro, 300 de la fábrica de gas, 1.000 dependientes de comercio, 800 trabajadores de empresas hosteleras, 1.000 de empresas periodísticas e imprentas, ...). Además, fueron anuladas 400 licencias de taxis por su paro los días de huel-

51 El nombramiento de Salazar Alonso se puede ver en El Debate, 20/10/34, p. 5; la opinión, en Labor, $1 / 12 / 34$, p. 5; la entrevista de Salazar Alonso con Gil Robles, en E/ Debate, $28 / 10 / 34$, p. 5; los miembros de la comisión gestora, en El Sol, 27/10/34, p. 8 y El Debate, $27 / 10 / 34$, p. 7 . Sobre el número de ayuntamientos suspendidos por provincias por los sucesos revolucionarios de octubre ver informe del Ministerio de Gobernación en AGGC, PS MLA. DRID, 1860.

Ili.ptumia, I.IX/3, núm. 203 (1999) 1063-1103 
ga, y se suspendieron las subvenciones municipales a sociedades obreras, aunque no se anularon las partidas para los fines a que estaban aplicadas: socorro por desempleo, enfermedad y accidentes de trabajo ${ }^{52}$.

Las organizaciones socialistas madrileñas estaban desmanteladas y sus dirigentes en la cárcel. Se estableció una Junta Administrativa Provisional de la Casa del Pueblo, formada por E. Domínguez, P. Sanjuán, L. Menéndez, S. González, y P. Gutiérrez, que se dedicó principalmente a intentar su reapertura $\mathrm{y}$ a ayudar a los presos socialistas y «as organizaciones obreras funcionaron minimamente estableciendo locales en distintas partes de Madrid). En la provincia, la situación era similar: la agrupación socialista de Alcalá de Henares informó que «el anterior secretario al ocurrir los sucesos de octubre ... quemó todos los libros de la Agrupación, ... hasta el extremo de que carecíamos de listas de afiliados); la de Navacerrada no se reunió hasta principios de 1936, por «la persecución y encarcelamiento de algunos camaradas»; la Casa del Pueblo de Colmenar Viejo estuvo clausurada hasta diciembre de 1935; la agrupación socialista de Barajas se resentía de tener a «nuestros directivos en la cárcel», y no volvió a funcionar hasta noviembre de 1935 , «en que sólamente contaba con cinco socios». Además, según Tagüeña, «toda la organización de la FUE se había desintegrado ... El fracaso de la revolución de octubre resolvió la pugna entre la FUE y la Falange en provecho de esta últiman ${ }^{53}$.

Los primeros Consejos de Guerra sumarísimos se celebraron en la Cárcel Modelo el 12 de octubre: las penas a los detenidos en plena comisión de delitos de rebelión (casi todos jóvenes) fueron muy duras: por llevar una bomba, 20 años de prisión; por repartir hojas "sediciosas", 12 años; por insulto a un guardia de asalto, 3 años y un día; ... Muchos miembros de las milicias fueron juzgados entonces por tribunales de urgencia. Pero destacan los procesos contra la Junta Administrativa de la Casa del Pueblo y contra G. Morón, por los hallazgos de armas de septiembre, y el de las milicias socialistas de Madrid. El primero se celebró el 14 de octubre de 1934. La defensa se basó en que en la Casa del Pueblo había multitud de sociedades que tenían vida sindical propia, por lo que la Junta Administrativa no podía saber que allí se guardasen armas. Se condenó a W. Carrillo, P. Tomás, A. García Atadell, R. Cortés, J. Gómez Egido y R. Henche a 3 años de prisión y al pago de una multa de 1.000 pesetas, por delito de depósito de armas y tenencia de exp̋losivos, y a $G$. Bruno Navarro a dos años de prisión y 1.000 pesetas de multa por depósito de armas. Se absolvió al

52 E/ Debate, $10 / 10 / 34$, p. 1, «Las organizaciones sindicales»; los miembros de la nueva organización vienen en $A B C, 19 / 10 / 34$, p. 27; las adhesiones, en El Debate, 30/10/34, p. 7. Los comunicados de Falange están recogidos en $A B C$, el de metaúrgicos, el 11/10/34, p. 22; el de gráficos, el 13/10/34, p. 20; los despidos, en Democratia, 13/7/35, p. 3, sobre los taxis, ver El Debate, $23 / 10 / 34$, p. 7 , sobre los subsidios, Tiempos Nuevos, 25/3/35, p. 9.

53 La primera cita es de Memoria de la Junta Administrativa..., op. cit., p. 5. FPI, sobre Alcalá de Henares ver $A H$ 16-24; sobre Navacerrada, $A H, 17-9$; sobre Colmenar Viejo, AASM, 16-37 (1); sobre Barajas, AASM, 16-31 (1). La última cita es de TAGül:Ñ , M., Testimonio de ..., op. cit., p. 83.

Hi.pankia, LIX/3, núm. 203 (1999) 1063-1103 
resto de los miembros de la Junta (eran otros diez, para los que el fiscal pedía un año de cárcel) por falta de pruebas o por no constituir delito los hechos que se les imputaba, y se decretó la disolución de las 45 sociedades copropietarias de la Casa del Pueblo. El 29 de octubre, G. Morón y C. López fueron condenados a 10 años, por tenencia de explosivos, y $\mathrm{C}$. López a uno más por tenencia ilícita de armas ${ }^{54}$.

El Consejo de Guerra contra las milicias socialistas se inició el 3 de enero de 1936. Aunque no se las acusó penalmente, se consideraba a las Juventudes Socialistas las organizadoras de las milicias: el informe del juez instructor decía que de las actuaciones «se deduce que hace largo tiempo las Juventudes Socialistas estaban organizándose para la revolución, constituyendo ... Milicias»; en la sentencia se planteaba que las milicias estaban «nutridas en su mayor parte de elementos de las Juventudes del Partido Socialista y personas afines». Se decidió no procesar a los simples militantes, aunque sí a individuos que no pertenecian a la estructura organizativa de las milicias, pero que habían tenido un papel importante en el tráfico de armas. Además, durante la preparación del sumario, algunos milicianos aprovecharon permisos vatios para escapar, mientras que algunos jefes de sector y de compañía no habian podido ser detenidos, ya que habían huido al extranjero (lo que es una muestra de organización), por lo que se hizo una causa aparte y se procesó en rebeldía a 13 individuos. Assí las cosas, se juzgó a 33 personas: el fiscal pedía la reclusión perpetua para el teniente Moreno y el guardia del Rey; para los milicianos, 6 penas de 15 años por responsabilidad de conspiración y auxilio para la rebelión; 18 de 12 años y un día por conspiración para la rebelión; tres de 3 años por depósito de armas, y la absolución, por falta de pruebas, del teniente Castillo, Perruca y Gañán. El 11 de enero se leyó la sentencia: el tribunal rebajó las penas de los civiles, pero sólo aceptó la absolución del teniente Castillo de los miembros de fuerzas del orden. Todos fueron amnistiados por el decreto de 21 de febrero de 1936, y el fiscal ordenó su puesta en libertad el día 22; también se consideró aplicable la amnistía a los procesados en rebeldía, por lo que se sobreseyó su proceso el 10 de marzo. En cuanto al desarrollo posterior de las milicias socialistas, Tagüeña dijo haber ayudado a «Ordoñez en la reorganización ... con el poco armamento salvado de nuestro fracaso anterion, tras las elecciones de febrero de 1936, aunque «en realidad, no étamos más que unos pocos centenares de hombres apenas armados» en julio de $1936^{55}$.

54 Las primeras condenas están recogidas en El Debate, 13/10/34, p. 6, y El Sol, 14/10/34, p. 8; los juicios sumarisimos a milicianos, en AGGC, PS NADRID, 1918, sexta pieza, E. 12. Sobre la Junta Administrativa de la Casa del Pueblo, ver las peticiones del fiscal en El Debate, 29/9/34, p. 3; la sentencia, en Memoria de la Junta Administrativa..., op. cit., pp. 9-21. La defensa utilizada por los abogados ya había sido planteada en E/Socialista, 22/9/34, p. 1, "Unas reflexiones sobre jos alijos y los complots».

55 Ver AGGC, SM, 345, f. 1082 verso, la primera cita; AGGC, SM, 347, ff. 2128 verso y 2129 recto, la segunda; en AGGC, SN $[, 345$, f. 1147, la decisión de no juzgar a los simples milicianos; AGGC, SM, 347, ff. 2-3, los procesados en rebeldía. Para las penas solicitadas, ver

IIiquatia, I.JX/3, núm. 203 (1999) 1063-1103 
Tras los sucesos de octubre, las distintas organizaciones obreras valoraton los sucesos revolucionarios y las causas de su fracaso. Parte del debate se centró en Madrid: el fracaso en la capital del Estado, sede del poder político, suponía el fracaso de la insurrección. La CNT consideró que desde el fracaso de los asaltos a centros oficiales en Madrid, «debió considerarse fracasado el golpe, pues aunque Cataluña y Asturias hubieran triunfado, al permanecer el grueso de las fuerzas al servicio del poder, ... la revolución tendría que ser forzosamente derrotada»; el PCE criticó al PSOE su concepción del trabajo en el ejército, orientado hacia los oficiales, y de las milicias, como órganos «exclusivamente del P.S.». Y Madrid había sido dirigida por el sector largocaballerista: así, la polémica estaba servida no sólo con las demás organizaciones obreras, sino dentro de las mismas organizaciones socialistas, dónde los ejemplos de este debate son numerosos, y la expresión más dura es la carta que los jóvenes socialistas de la cárcel de Oviedo dirigieron a la ejecutiva nacional de la FJS: «los jóvenes que hemos luchado en las barricadas necesitamos saber por qué habéis sido detenidos antes de estallar la revolución; por qué 90.000 [sic] brazos del Metropolitano de Madrid han quedado petrificados; por qué mientras permanecíamos los asturianos empuñando el fusil se ordenaba la vuelta al trabajom. Miembros del sector caballerista justificaron la táctica adoptada: Araquistain situó como principal defecto la falta de «directores militares», pero consideró que la táctica seguida "prolongada, acaba agotando los nervios de la fuerza pública»; Ramos Oliveira planteó que en Madrid "se pudo hacer más de lo que se hizon y había fallado la organización; pero no se podía asegurar que «la huelga general y la agitación de grupos decididos no crearían, de asegurarse algún tiempo, buena parte de las condiciones revolucionarias objetivas inexistentes al comenzar la revolución'. En diciembre de 1935, al aprobarse por la mayoría del Comité Nacional del PSOE que la minoría parlamentaria quedase supeditada a la Comisión Ejecutiva y al Comité Nacional, Largo Caballero dimitió de su cargo de presidente. La mayoría de los milicianos, y presos socialistas en general, madrileños, al igual que las organizaciones socialistas de esta provincia, apoyaron a Largo: mientras E/ Socialista sólo pudo citar, entre las adhesiones madrileñas a la ejecutiva, las de 11 presos, Claridad incluyó una larga lista de apoyos a Largo Caballero, con casi todos los dirigentes de las juventudes, de la Casa del Pueblo y los milicianos (aunque no los tres miembros del comité revolucionario de Madrid). Pero la represión también favoreció la unidad de acción entre las distintas organizaciones, y se desarrollaron las Alianzas Obreras en el ámbito provincial: en mayo-junio de 1935 existía una alianza local en la capital, que mantenía parecida composición a la existente antes de octubre, alianzas de distrito (radio este y radio sur), y alianzas locales en Chamartín, Carabanchel Alto y Bajo. En diciembre de 1935, ya existían en Canillas, Cani-

AGGC, SM, 347, f. 1821; las condenas, en AGGC, SM, 347, ff. 2133-2134; la amnistía, en AGGC, SM, 347, f. sin n ${ }^{\circ}$. TAGÜENA, M., Testimonio de..., op. cit., la primera cita en p. 89; la segunda en p. 90. 
llejas y Vicálvaro. Pero, excepto la del municipio de Madrid, estaban formadas sólo por las organizaciones socialistas y comunistas, pareciendo simples comités de enlace entre ellas ${ }^{56}$.

\section{A MODO DE CONCLUSIÓN}

Podemos considerar los sucesos de octubre en Madrid como el primer intento producido en la capital de acción colectiva insurreccional que intentaba seguir el modelo bolchevique. El instrumento eran las milicias socialistas de Madrid, que configuran un nuevo tipo de organización para un nuevo tipo de acción colectiva, que rompió con la tradición socialista anterior y que culminó en un auténtico fracaso. Aunque fue la movilización obrera más importante del Madrid republicano, la huelga general más extensa y el intento insurreccional más sostenido en la historia de la capital, en ningún momento se configuró una situación de soberanía múltiple, característica principal de las situaciones revolucionatias: el gobierno mantuvo el control de todos los órganos de dirección política y de las distintas fuerzas del orden del Estado. La acción acabó asumiendo unas características similares a las huelgas generales políticas anteriores: una acción disruptiva de enfrentamiento, dirigida contra sinstituciones, elites, autoridades u otros grupos en nombre de objetivos o actores colectivos o representantes de aquellos que hacen la reclamacións, que, según Tarrow, rechaza la mediación institucional; provoca desorganización, normalmente interrupción de procesos económicos y políticos y de la rutina diaria; es expresiva, porque las demandas son presentadas con cargas simbólicas y en términos no negociables; y es estratégica en su elección de recursos, objetivos y momento ${ }^{57}$.

Pata entender este fracaso no valen las explicaciones existentes, dadas por protagonistas, como Rosal, que planteó que los preparativos estaban incompletos, o Munis, que consideró como causa del fracaso la falta de poder efectivo y de dirección de la Alianza Obrera; o por historiadores, como S. Juliá, que sitúan las causas en la incapacidad de la UGT, por sus características y estructura, de realizar una insurrección, y en la subordinación de las acciones insurreccionales

56 La cita de la CNT procede de «Análisis de la revolución», recogido en BizCAnrondo, M., Octubre 1934. Reflexiones sobre una revolución, Madrid, Ayuso, 1977, pp. 300-301; las del PCE, de "Los combates de Octubre», en Bizcarrondo, M., Octubre 1934..., op. cit, pp. 191-207; la carta, en FPI, AH 26-11, f. 3; ARAQUISTAIN, L., «La revolución española...», op. cit., pp. 20-21; Ranos Oı.rveira, A., La revolución..., op. cit., la primera cita en p. 91, la segunda en p. 98. Para las adhesiones, ver E/Socialista, 4/1/36, p. 1, y 12/1/36, p. 1, y Claridad, 4/1/36, p. 3. Los informes sobre las alianzas obreras se encuentran en APCE, film XIII (170). Ya una octavilla de la Juventud Comunista de Madrid, de fecha muy cercana a los sucesos de octubre, informaba de la formación de un comite de enlace entre ella y las Juventudes Socialistas en Madrid (APCE, film VIII (115).

57 Para las situaciones revolucionarias ver TILLY, C., Las revaluciones europeas (1492-1992), Barcelona, Crítica, 1995, pp. 27-28; las características de las acciones disruptivas, en TAlRow, S., Democracy and disorder ..., op. cit., p. 14. Aunque este tipo de acciones no son necesariamente violentas, la forma más directa supone la amenaza de usarla, y su última forma es la violencia abierta.

Hihptutu, I.IX/3, núm. 203 (1999) 1063-1103 
a la huelga (la burocratización y la radicalización tardia de la UGT, por presiones de la base, se produjo también en el sindicato minero asturiano y, como hemos visto, la organización sindical no era el instrumento de la insurrección, ni ésta se subordinaba a la huelga) ${ }^{58}$. La explicación debe partir de la falta de una concepción unitaria o hegemónica entre los trabajadores en cuanto a objetivos, estrategias e instrumentos de la transformación, al igual que ocurrió en otros países europeos, como Alemania o Austria, y la combinación de los elementos que determinan las acciones colectivas. El planteamiento desde ciertos sectores obreros de una revolución socialista perjudicaba los intereses de aliados potenciales, como la pequeña burguesía republicana; la elección del momento político quedó supeditada a una acción del gobierno, que mantuvo así todos los resortes del poder, no dando lugar a una estructura de oportunidades políticas favorable. Con relación a la organización, no hubo una política de alianzas clata ni una coordinación entre las organizaciones participantes. Y, por último, pero no menos importante, la movilización de recursos fue deficiente en armamentos, contactos con militares y conformación de la organización para la insurrección; además de en lograr una aceptación colectiva de los nuevos tipos de actuación: debía ser difícil para las bases de la UGT pasar de una concepción reformista y pacífica a una «identidad» revolucionaria y violenta, como la que intentaron desde la prensa, tanto nacional como local, y discursos imbuirles sus dirigentes.

58 Rosal, A. del, 1934, El movimiento..., op. cit., p. 317; Munis, G., Jalones de derrota.., op. cit, p. 165. Jus.In, S., «Fracaso de una insurrección ...», op. cit., passim.

It:punia, L.IX/3, núm 203 (1999) 1063-1103 